\title{
VALIDACIÓN JUDICIAL DE ACUERDOS PRIVADOS DE REORGANIZACIÓN: UN EJEMPLO DE LA "PRIVATIZACIÓN" DEL DERECHO CONCURSAL EN COLOMBIA*
}

\author{
JUDICIAL VALIDATION OF PRIVATE \\ RESTRUCTURING AGREEMENTS. AN \\ EXAMPLE OF "PRIVATIZATION" OF THE \\ INSOLVENCY LAW IN COLOMBIA
}

\author{
Diana Lucía Talero Castro** \\ Rafael E. Wilches Durán ***
}

Fecha de recepción: 18 de marzo de 2010

Fecha de aceptación: 22 de abril de 2010

* El presente artículo es un producto del proyecto "Interpretación y aplicación del derecho privado - Autonomía privada y buena fe" del Grupo de investigación en Derecho Civil y Comercial de la Facultad de Ciencias Jurídicas de la Pontificia Universidad Javeriana.

** Diana Lucía Talero Castro es abogada y especialista en Derecho de Sociedades de la Pontificia Universidad Javeriana. Ha sido funcionaria de la Superintendencia de Sociedades de Colombia desde el año 1997, gracias a lo cual ha actuado en diversos cargos dentro de dicha entidad, todos relacionados con procedimientos mercantiles; actualmente se desempeña como asesora del superintendente de Sociedades. Participó en la comisión redactora del actual régimen de insolvencia empresarial colombiano (L. 1116/2006) y ha sido líder en la expedición de los decretos reglamentarios de tal ley y en la representación de Colombia en las reuniones periódicas de diferentes grupos de trabajo de la CNUDMI (Comisión de las Naciones Unidas para el Derecho Mercantil Internacional) y del Banco Mundial.

Correo: DianaT@supersociedades.gov.co

*** Rafael E. Wilches Durán es abogado y magíster en Derecho Económico de la Pontificia Universidad Javeriana. Laboró como funcionario de la Superintendencia de Sociedades y luego como promotor de acuerdos de reestructuración y reorganización de empresas insolventes. Actualmente se desempeña como profesor de planta del Departamento de Derecho Privado de la Facultad de Ciencias Jurídicas de la Pontificia Universidad Javeriana, profesor de cátedra en la Facultad de Derecho de la Universidad de la Sabana, y cursa estudios de doctorado en derecho en la Facultad de Jurisprudencia de la Universidad del Rosario. Participó en la comisión redactora del actual régimen de insolvencia empresarial colombiano (L. 1116/2006). Es miembro del Instituto Iberoamericano de Derecho Concursal Capítulo Colombiano.

Contacto: rwilches@javeriana.edu.co 


\section{RESUMEN}

El artículo 84 de la Ley 1116 del 2006 introdujo al ordenamiento jurídico colombiano una norma que permite que acuerdos privados de reorganización tengan los mismos efectos que los celebrados dentro de un procedimiento judicial de insolvencia de los regulados por dicha ley. Con lo anterior, el derecho colombiano da otro paso adelante en lo que podría denominarse la "privatización del Derecho concursal", fenómeno que viene observándose desde años atrás, no sólo en Colombia sino en diversos ordenamientos jurídicos. En el presente artículo se realiza un estudio detallado de la figura de la validación judicial de acuerdos privados de reorganización en Colombia, para comprender los efectos e implicaciones que la misma posee con respecto al Derecho concursal colombiano.

Palabras clave: insolvencia, reorganización empresarial, acuerdos privados, validación judicial, autonomía privada, derecho concursal.

Palabras clave descriptor: Reorganización de corporaciones, quiebra, derecho comercial.

\section{ABSTRACT}

Article 84 of Law 1116 of 2006 (Colombian insolvency regime) created in Colombian law the possibility to turn into mandatory for all the creditors of an insolvent debtor the private agreement made between the majority of those creditors and the debtor. This is a completely new institution in Colombian law and turns into an example of what has been called the "privatization" of insolvency law. This article studies the institution of judicial recognition of private agreements in Colombia, in order to comprehend its implications for Colombian insolvency law.

Key words: insolvency, reorganization agreements, private agreements, judicial recognition, private autonomy, insolvency law.

Key words plus: Corporate Reorganizations, Bankruptcy, Commercial law 


\section{INTRODUCCIÓN}

El fenómeno de la insolvencia, entendido en sentido amplio, como aquel que se presenta cuando un deudor no puede satisfacer en los términos pactados las obligaciones a su cargo, con lo cual quedan cobijados dentro de tal término figuras como la iliquidez, la insolvencia en sentido estricto, la cesación de pagos, la incapacidad de pago inminente, entre otras, ha recibido el más diverso trato a través de la historia ${ }^{1}$. En efecto, desde la manus injectio del derecho romano, pasando por la concepción penal de la quiebra, no muy lejana históricamente, hasta la comprensión de la insolvencia como un fenómeno esencialmente económico, que no amerita la imposición de sanciones penales sino sólo de orden civil, han sido muy diversas las concepciones y consecuencias de orden jurídico que se le han otorgado a tal fenómeno.

Asistimos hoy en día a un momento en que, por lo menos en lo que a derecho colombiano se refiere, la autonomía privada incursiona cada vez con mayor fuerza dentro de las instituciones que tradicionalmente se han manejado en materia de derecho concursal, tanto en materia de procesos de recuperación o salvamento como en procesos de liquidación del patrimonio del deudor. Reflejo de ello es la figura de validación judicial de acuerdos privados o extrajudiciales de reorganización ${ }^{2}$, introducida al ordenamiento jurídico colombiano por el artículo 84 de la Ley 1116 del 2006 y reglamentada actualmente por el Decreto 1730 del 2009, y a cuyo estudio dedicamos el presente artículo.

\section{LA FIGURA DE VALIDACIÓN JUDICIAL DE ACUERDOS PRIVADOS DE REORGANIZACIÓN}

En este acápite presentamos una descripción de la figura, con base en las normas que regulan el tema y la escasa doctrina nacional existente sobre la misma, así:

\section{Definición}

El artículo 84 de la Ley 1116 del 2006 dispone:

"Artículo 84. Validación judicial de acuerdos extrajudiciales de reorganización. Cuando por fuera del proceso de reorganización, con el consentimiento del deudor, un número plural de acreedores que equivalga a la mayoría que se requiere en la presente ley para celebrar un acuerdo de reorganización,

1 Cfr. Jesús María Sanguino Sánchez. Cesación de pagos en los procedimientos concursales. págs. 33 - 42. Ediciones Librería del Profesional. Bogotá D.C. 1a edición. (1982).

2 Cfr. Juan José Rodríguez Espitia. Nuevo régimen de insolvencia. págs. 587-588. Universidad Externado de Colombia. Bogotá D.C. $1^{a}$ Edición. (2007). 
celebren por escrito un acuerdo de esta naturaleza, cualquiera de las partes de dicho acuerdo podrá pedir al juez del concurso que hubiere sido competente para tramitar el proceso de reorganización, la apertura de un proceso de validación del acuerdo extrajudicial de reorganización celebrado, con el fin de verificar que este:

"1. Cuenta con los porcentajes requeridos en esta ley.

" 2 . Deja constancia de que las negociaciones han tenido suficiente publicidad y apertura frente a todos los acreedores.

"3. Otorga los mismos derechos a todos los acreedores de una misma clase.

"4. No incluye cláusulas ilegales o abusivas, y

"5. En términos generales, cumple con los preceptos legales.

"El proceso de validación tendrá en consideración las reglas sobre notificación establecidas en esta ley, las reglas para la calificación y graduación de créditos y votos, y las demás que en lo relativo a su forma y sustancia le sean aplicables, incluyendo los efectos jurídicos a que hace referencia el artículo 17 y el capítulo IV de la presente ley.

"Si como resultado del proceso de validación el juez del Concurso autoriza el acuerdo, este tendrá los mismos efectos que la presente ley confiere a un acuerdo de reorganización.

"Incumplido el acuerdo de reorganización extrajudicial, se aplicarán las normas que para el efecto están establecidas para el incumplimiento del acuerdo de reorganización de que trata la presente ley".

Así, la citada norma crea un mecanismo encaminado a que el deudor insolvente y sus acreedores, de manera privada, negocien un acuerdo de reorganización, de suerte que cuando el mismo sea aprobado por tal deudor y la mayoría de dichos acreedores, de conformidad con las reglas de votación que establece el mismo régimen de insolvencia, tal acuerdo pueda ser sometido a un proceso de validación ante autoridad judicial competente, para que tenga los mismos efectos de un acuerdo de reorganización celebrado dentro de un proceso judicial de reorganización, los cuales consisten, básicamente, en la imposición de lo decidido por la mayoría de acreedores a los ausentes y disidentes, y en la imposibilidad de iniciar o continuar procesos en contra del deudor por concepto de las obligaciones objeto del acuerdo de reorganización.

$\mathrm{El}$ origen de esta figura puede encontrarse, pues, como consecuencia de una concepción que privilegia los acuerdos directos y privados, celebrados entre las personas y entes afectados como consecuencia de la situación de insolvencia de un deudor, sobre aquellos esquemas formalistas e intervencionistas, que obligan a que el Estado, a través de procesos cuyas formas y términos son ampliamente regulados, intervenga cada vez que se presenta una situación de insolvencia de un deudor sujeto a su jurisdicción ${ }^{3}$.

3 Cfr. Álvaro Isaza Upegui, \& Álvaro Londoño Restrepo. Comentarios al régimen de insolvencia 
De hecho, bajo esta concepción "privatista" del derecho concursal, se privilegian las soluciones que emanen directamente de los socios o los acuerdos estrictamente privados, sobre cualquier otra figura, como vía para solucionar las situaciones de insolvencia ${ }^{4}$. Sin embargo, la desventaja de los acuerdos estrictamente privados es que sólo obligan a quienes expresamente otorguen su consentimiento para el efecto, pues están gobernados por el postulado de la relatividad de los actos jurídicos, que caracteriza a los contratos y de conformidad con el cual, salvo excepciones legales, los mismos "(...) no producen derechos ni obligaciones para las personas enteramente ajenas a su celebración", , lo que se traduce en un efecto de la concepción según la cual "(...) la participación voluntaria o consentimiento es requisito esencial para la radicación subjetiva de los mencionados efectos de los actos jurídicos".

Como consecuencia de lo anterior, los acuerdos privados serían la mejor solución disponible para un deudor que desee hacer el menor "ruido" posible sobre las dificultades por las que está atravesando, bajo el entendido de que tenga la mayoría de sus deudas concentradas en acreedores que estén dispuestos, por voluntad propia, a prestarle su apoyo en esos momentos difíciles y lograr así negociar dentro de un escenario de comunidad de intereses antes que de comunidad de pérdidas 7 . Por el contrario, cuando no se dan los supuestos necesarios para negociar un acuerdo privado, bien sea, entre otros, porque las deudas están dispersas en muchos acreedores o porque el inicio de negociaciones de un acuerdo privado pone en riesgo la continuidad de la empresa, ya que se conoce de antemano, por ejemplo, que algunos de los principales acreedores no están dispuestos a ceder en sus pretensiones de pago inmediato de las obligaciones a su favor, surge la necesidad de que el Estado a través del ordenamiento jurídico brinde protección a tales deudores, con figuras que permitan que todos los acreedores y todos los bienes se vean afectos por un único proceso de insolvencia en que, bajo condiciones de igualdad, sea la mayoría de los acreedores la que decida cuál es la suerte que debe correr el deudor insolvente y su patrimonio ${ }^{8}$. Es en esta última hipótesis en la que surge la figura de los procesos concursales de recuperación o salvamento de los negocios del deudor insolvente, regulada en nuestro ordenamiento bajo las denominaciones de concordato preventivo del Código

empresarial - Ley 1116 del 2006. págs. 249 - 251. Legis Editores S.A. $2^{a}$ edición. Bogotá D.C. (2008).

4 Cfr. Efraín Hugo Richard. Insolvencia societaria. págs. 162 - 168. Lexis Nexis. Argentina S.A. $1^{\text {a }}$ edición. Buenos Aires. (2007).

5 Guillermo Ospina Fernández \& Eduardo Ospina Acosta. Teoría general del contrato y de los demás actos o negocios jurídicos. Pág. 362. Editorial Temis S.A. Cuarta edición actualizada. Bogotá D.C. (1994).

6 Guillermo Ospina Fernández \& Eduardo Ospina Acosta. Teoría general del contrato y de los demás actos o negocios jurídicos. Pág. 362. Editorial Temis S.A. Cuarta edición actualizada. Bogotá D.C. (1994).

7 Cfr. Álvaro Isaza Upegui \& Álvaro Londoño Restrepo. Comentarios al régimen de insolvencia empresarial - Ley 1116 del 2006. Pág. 254. Legis Editores S.A. 2a edición. Bogotá D.C. (2008).

8 Cfr. Juan José Rodríguez Espitia. Nuevo régimen de insolvencia. Pág. 586. Universidad Externado de Colombia. 1a. Edición. Bogotá D.C. (2007). 
de Comercio (Decreto 410 de 1971) ${ }^{9}$, concordatos preventivos potestativo y obligatorio del Decreto 350 de $1989^{10}$, el concordato de la Ley 222 de $1995^{11}$, los acuerdos de reestructuración de la Ley 550 de 1999 y el actual acuerdo de reorganización de la Ley 1116 del 2006. Todas las anteriores figuras, que obviamente gozan de particularidades que hacen a cada una muy distinta de las otras, tienen en común el hecho que la negociación del acuerdo de salvamento se ha dado dentro de un proceso regulado detalladamente por la ley, bajo la dirección o vigilancia, según sea el caso, de una autoridad, bien sea judicial o administrativa, y que el acuerdo aprobado por las mayorías que ha exigido la ley se ha convertido en obligatorio para los acreedores ausentes y disidentes en la toma de tal decisión.

La figura regulada por el artículo 84 de la Ley 1116 del 2006 se encuentra en una etapa intermedia entre los acuerdos estrictamente privados y el proceso judicial de los acuerdos de reorganización regulados por la misma ley. En efecto, el acuerdo regulado en el mencionado artículo 84 se celebra en el marco de negociaciones privadas, pero el mismo es presentado ante una autoridad, en este caso judicial, para que ella examine los requisitos de validez de tal acuerdo privado y le otorgue los mismos efectos que uno celebrado dentro de un proceso judicial de reorganización. La extrajudicialidad de su enunciado, por tanto, es relativa, pues ella sólo aparece en la etapa de negociación y celebración del acuerdo. Esa naturaleza híbrida de los acuerdos privados que son validados judicialmente hace que los mismos gocen de ciertas características de las figuras que se encuentran en sus extremos, como veremos posteriormente.

En general, puede afirmarse que la introducción de la institución de la validación judicial de acuerdos privados al ordenamiento jurídico colombiano obedece a la necesidad de una respuesta temprana y activa de los principales acreedores del deudor insolvente, la que normalmente no es posible en el régimen judicial de reorganización. De hecho, lo que se persigue con dicha figura es darle espacio a la negociación privada, para obtener un acuerdo celebrado en el marco de un procedimiento con menor confrontación entre los actores y menor estigmatización con respecto al deudor, a la vez que más flexible que el proceso judicial de reorganización regulado en la misma ley.

Así, el proceso de validación judicial de acuerdos extrajudiciales de reorganización, introducido al ordenamiento jurídico colombiano por el artículo 84 de la Ley 1116 del 2006 y reglamentado actualmente por el Decreto 1730

9 Ver, entre otros, Darío Londoño SALDARriaga. El concordato preventivo. Editorial Temis. S.C.A. $1^{a}$ edición. Bogotá D.C. (1982).

10 Ver, entre otros, Gustavo Cuberos Gómez. Comentarios al régimen de concordatos comerciales Decreto 350 de 1989. Ediciones Doctrina y Ley. $2^{\mathrm{a}}$ edición actualizada. Bogotá D.C. (1993).

11 Ver, entre otros, HiLdeBrando LeAL Pérez. Los procesos concursales y los acuerdos de reestructuración empresarial. Editorial Leyer Ltda. $4^{\text {a }}$ edición. Bogotá D.C. (2001). 
del 2009, configura un proceso alternativo al proceso formal de reorganización, que tiene como característica la celebración privada y no procesal del acuerdo, con la previsión de un proceso reglado en una etapa judicial final, la exigencia de una mayoría igual que la exigida en un proceso judicial de reorganización, unos requerimientos de publicidad de la negociación para los acreedores, un procedimiento de oposición bajo causales previamente delimitadas frente a la determinación de los créditos y votos, y frente al acuerdo mismo, con miras a la obtención judicial de su validación, lo que se traduce en el otorgamiento de los mismos efectos predicables de un acuerdo gestado dentro de un proceso judicial de reorganización.

En conclusión, pues, puede definirse la validación de acuerdos privados de reorganización como aquella figura consistente en un acuerdo que se instrumenta en forma conjunta entre los acreedores y el deudor, bajo reglas de aprobación por mayorías, en donde la manifestación de voluntad se hace a través de documento escrito firmado por el deudor y un número plural de acreedores que equivalga a la mayoría absoluta de los votos correspondientes a todos los acreedores ${ }^{12}$, que se impone a los ausentes o disidentes ${ }^{13}$, mediante el trámite de un proceso de validación judicial, cuya consecuencia es que, una vez autorizado el acuerdo mediante el proceso de validación judicial, se le aplicarán las reglas de cumplimiento o incumplimiento dispuestas en la Ley 1116 del 2006 para los acuerdos judiciales de reorganización.

\section{Antecedentes de la figura}

La figura de validación judicial de acuerdos privados no tiene antecedentes normativos en nuestro ordenamiento jurídico colombiano. En efecto, aunque se hable de figuras similares, no hay un antecedente que se ajuste de manera estricta a lo regulado por el artículo 84 de la Ley 1116 del 2006.

De hecho, la primera norma que eventualmente podría mencionarse como antecedente de la que es objeto de este estudio, fue el artículo 47 del Decreto 350 de 1989, que regulaba el evento en que el acuerdo concordatario fuera celebrado de manera privada y fuera presentado luego para su aprobación por el juez del concurso, de manera que tal acuerdo tuviera los mismos

12 Ley 1116 del 2006. Artículo 31.

13 El artículo 29 del Decreto 1730 del 2009, reglamentario del artículo 84 de la Ley 1116 del 2006 dispone: “(...) El acuerdo, una vez autorizado tendrá las formalidades y los efectos de que trata el capítulo VII de la Ley 1116 del 2006", entre ellos, el dispuesto en el artículo 40 de la Ley 1116 del 2006, que dispone que “(...) como consecuencia de la función social de la empresa, los acuerdos de reorganización y los acuerdos de adjudicación celebrados en los términos previstos en la presente ley, serán de obligatorio cumplimiento para el deudor o deudores respectivos y para todos los acreedores, incluyendo a quienes no hayan participado en la negociación del acuerdo o que, habiéndolo hecho, no hayan consentido en él”. 
efectos que el acuerdo concordatario. Disposición similar fue la consagrada posteriormente por el artículo 142 de la Ley 222 de 1995.

Sobre el particular hay que mencionar que tales normas regulaban una hipótesis muy similar, pero completamente distinta de la regulada por el artículo 84 de la Ley 1116 del 2006. Ello, por cuanto las regulaciones del Decreto 350 de 1989 y de la Ley 222 de 1995 partían de la existencia de un proceso judicial concursal para el momento de la negociación y celebración del acuerdo concordatario, mientras que el acuerdo privado que se presenta para validación en virtud de lo dispuesto por el artículo 84 de la Ley 1116 del 2006 se celebra en un marco estrictamente privado, es decir, cuando no hay ningún proceso judicial concursal de por medio ${ }^{14}$. Es decir, bajo los regímenes del Decreto 350 de 1989 y la Ley 222 de 1995 nunca se contempló la posibilidad de que un acuerdo negociado en un ámbito estrictamente privado fuera presentado para validación del juez del concurso; bajo tales regímenes siempre fue indispensable que el proceso ya hubiera iniciado formalmente ante la autoridad judicial, para que luego pudiera presentarse ante la misma un acuerdo celebrado por fuera de audiencia, con el fin de que éste fuera aprobado y tuviera los mismos efectos que un acuerdo concordatario. La Ley 550 de 1999 tuvo un talante muy distinto de los regímenes de 1989 y 1995, pues la inspiró un matiz claramente contractualista ${ }^{15}$, pero tampoco contempló una figura similar a la del artículo 84 de la ley del 2006.

Por su parte, figuras como la de los artículos 205 de la Ley 222 de 1995 y 66 de la Ley 1116 del 2006, que regulan la hipótesis de un acuerdo concordatario o de reorganización por fuera de audiencia del trámite de liquidación del deudor insolvente, son igualmente distantes de la figura del artículo 84 de la Ley 1116 del 2006, por las razones anteriormente mencionadas, pues en esta última norma el supuesto es el de que no existe proceso de insolvencia en curso, sino que a un acuerdo estrictamente privado se le otorga la posibilidad de ser sometido a un proceso de validación ante autoridad judicial, para obtener los mismos efectos de un acuerdo de salvamento celebrado dentro de un proceso judicial.

Ciertos doctrinantes mencionan como antecedente de la validación judicial de acuerdos privados a las reestructuraciones extraordinarias reguladas por la Circular 039 de 1999 de la Superintendencia Bancaria de Colombia. Sin embargo, como ellos mismos lo reconocen, “(...) para su validez, se requería que estos acuerdos comprendieran por lo menos el ochenta por ciento $(80 \%)$ del total adeudado al sector financiero. Pero, contra lo que podría esperarse, la obtención de la mayoría indicada no hacía extensivos los efectos del acuerdo

14 Cfr. Álvaro Isaza Upegul y Álvaro Londoño Restrepo. Comentarios al régimen de insolvencia empresarial - Ley 1116 del 2006. Pág. 251. Legis Editores S.A. $2^{a}$ edición. Bogotá D.C. (2008).

15 Cfr. Exposición de motivos de la Ley 550 de 1999. Transcrita en Claudia Álvarez Vejarano. Ley 550 - Manual de interpretación. Págs. 117-132. 3R Editores Ltda. 1ª edición. Bogotá D.C. (2000). 
a los acreedores que no lo suscribieran, lo cual ubica estos acuerdos, desde el punto de vista de sus efectos, dentro del marco del derecho privado, dada su relatividad, y no dentro de los principios del concurso -así fuera para el universo constituido por los acreedores del sector financiero- que desborda dicha relatividad"16. Con lo anterior, queda claro que la figura regulada por la Circular 039 de 1999 de la Superintendencia Bancaria no es equiparable a la del artículo 84 de la Ley 1116 del 2006, pues su finalidad era, primordialmente, regular las condiciones bajo las cuales estaban siendo negociados acuerdos estrictamente privados entre entidades financieras y deudores insolventes, tanto para incentivar la celebración de dichos acuerdos, por ejemplo, cuando se establecía que las calificaciones de créditos reestructurados tenían un tratamiento distinto de las de aquellos deudores que no hubieran celebrado uno de tales acuerdos, como regular las condiciones que las entidades financieras podían aceptar, de manera que no incurrieran en riesgos insalvables para el sistema financiero ${ }^{17}$.

Por su parte, otro doctrinante menciona como antecedentes de la figura las observaciones de la CNUDMI (Comisión de las Naciones Unidas para el Derecho Mercantil Internacional) sobre procedimientos de pre-insolvencia o planificados, mediante los cuales se ofrezca "(...) un medio por el cual un plan negociado voluntariamente por un deudor, con alguno o todos sus acreedores, pueda, con todo, ser aprobado sin el apoyo unánime de ellos, pero que permita concertar una reorganización que los vinculará a todos, incluso a los disconformes, con lo cual se minimiza el costo y los retrasos inherentes a los procedimientos oficiales" 18 , así como el acuerdo preventivo extrajudicial o APE de la legislación argentina ${ }^{19}$. En efecto, sobre este último punto hay que mencionar que las leyes 22.917 de 1983, 24.522 de 1995 y 25.589 del 2002 de la República Argentina regulan una figura denominada como se mencionó anteriormente, de naturaleza muy similar a la regulada por el artículo 84 de la Ley 1116 del 2006, pero que goza de ciertas diferencias, como por ejemplo, la determinación de mayorías, que la hacen muy distinta de la figura colombiana ${ }^{20}$. No es objeto del presente artículo efectuar una comparación con tal institución de la legislación argentina ni con lo que sobre este tipo

16 Álvaro Isaza Upegul y Álvaro Londoño Restrepo. Comentarios al régimen de insolvencia empresarial - Ley 1116 del 2006. Pág. 248. Legis Editores S.A. $2^{a}$ edición. Bogotá D.C. (2008).

17 Cfr. Álvaro Isaza Upegui y Álvaro Londoño Restrepo. Comentarios al régimen de insolvencia empresarial - Ley 1116 del 2006. Págs. 247-248. Legis Editores S.A. $2^{\mathrm{a}}$ edición. Bogotá D.C. (2008).

18 Juan José Rodríguez Espitia. Nuevo régimen de insolvencia. Pág. 586. Universidad Externado de Colombia. $1^{a}$ edición. Bogotá D.C. (2007).

19 Cfr. Juan José Rodríguez Espitia. Nuevo régimen de insolvencia. Págs. 586-587. Universidad Externado de Colombia. $1^{\mathrm{a}}$ edición. Bogotá D.C. (2007).

20 Ver, entre otros, Ignacio A. Escuti \& Francisco Junyent Bas. Derecho concursal. Págs. 439-465. Buenos Aires. Editorial Astrea. $1^{a}$ edición. (2006); y AA.VV. Acuerdo preventivo extrajudicial del deudor y sus garantes. En Alfredo Rovira (director). Empresa en crisis. Págs. 109-152. Editorial Astrea. $1^{a}$ edición. Buenos Aires. (2005). 
de figuras ha dicho la CNUDMI, sino efectuar, por el momento, un estudio de la validación judicial de acuerdos privados desde el derecho interno, teniendo como sustento lo dispuesto por el artículo 84 de la Ley 1116 del 2006 y el Decreto 1730 del 2009.

\section{El acuerdo como tal}

El objeto de la figura es el de preservar empresas viables y normalizar sus relaciones comerciales y crediticias, mediante la reestructuración operacional, administrativa y de activos o pasivos del deudor insolvente ${ }^{21}$.

Para ello, la misma aplica con respecto a deudores personas naturales comerciantes $^{22}$, las personas jurídicas no excluidas del régimen de insolvencia empresarial ${ }^{23}$, las sucursales de sociedades extranjeras y los patrimonios autónomos afectos a la realización de actividades empresariales ${ }^{24}$.

21 Ley 1116 del 2006. Artículo $2^{\circ}$.

22 Las personas naturales no comerciantes no están cobijadas por la regulación de la Ley 1116 del 2006, por lo cual la figura prevista en el artículo 84 de la misma no tendría aplicación respecto de ellos. Adicionalmente, la Ley 1380 del 2010, que regula la insolvencia de las personas naturales no comerciantes, no previó la posibilidad de validación judicial de acuerdos privados que se celebren con respecto a dichos deudores.

23 Sobre el particular, la Ley 1116 del 2006 dispone:

"Artículo 2․ Ámbito de aplicación. Estarán sometidas al régimen de insolvencia las personas naturales comerciantes y las jurídicas no excluidas de la aplicación del mismo, que realicen negocios permanentes en el territorio nacional, de carácter privado o mixto. Así mismo, estarán sometidos al régimen de insolvencia las sucursales de sociedades extranjeras y los patrimonios autónomos afectos a la realización de actividades empresariales.

"El Gobierno Nacional establecerá los requisitos de admisión de dichos patrimonios autónomos al trámite de insolvencia a que se refiere la presente ley.

"Artículo $3^{\circ}$. Personas excluidas. No están sujetas al régimen de insolvencia previsto en la presente ley:

"1. Las Entidades Promotoras de Salud, las Administradoras del Régimen Subsidiado del Sistema General de Seguridad Social en Salud y las Instituciones Prestadoras de Servicios de Salud.

"2. Las Bolsas de Valores y Agropecuarias.

“3. Las entidades vigiladas por la Superintendencia Financiera de Colombia. Lo anterior no incluye a los emisores de valores, sometidos únicamente a control de la referida entidad.

"4. Las entidades vigiladas por la Superintendencia de Economía Solidaria que desarrollen actividades financieras, de ahorro y crédito.

"5. Las sociedades de capital público, y las empresas industriales y comerciales del Estado nacionales y de cualquier nivel territorial.

"6. Las entidades de derecho público, entidades territoriales y descentralizadas.

"7. Las empresas de servicios públicos domiciliarios.

"8. Las personas naturales no comerciantes.

“9. Las demás personas jurídicas que estén sujetas a un régimen especial de recuperación de negocios, liquidación o intervención administrativa para administrar o liquidar.

"Parágrafo. Las empresas desarrolladas mediante contratos que no tengan como efecto la personificación jurídica, salvo en los patrimonios autónomos que desarrollen actividades empresariales, no pueden ser objeto del proceso de insolvencia en forma separada o independiente del respectivo o respectivos deudores".

24 Los patrimonios autónomos afectos a actividades empresariales para los efectos de la aplicación de la Ley 1116 del 2006 son aquellos que tienen por objeto principal adelantar en forma organizada la administración o custodia de bienes destinados a procesos de producción, transformación, circulación o prestación de servicios, según lo dispuesto en el artículo $1^{\circ}$ del Decreto 1038 del 2009. 
Se ha interpretado que están expresamente excluidos los deudores que se encuentren tramitando un proceso judicial de reorganización, de acuerdo con el encabezado del artículo 84 de la Ley 1116 del 2006, que prescribe: “(...) Cuando por fuera del proceso de reorganización, (...)”. Aparejado con lo anterior, se discute si también están excluidos aquellos deudores que estén tramitando un proceso de liquidación judicial, un proceso de liquidación obligatoria, o que estén en trámite o cumplimiento de un acuerdo concordatario o de reestructuración. Al respecto consideramos que las normas de cada proceso concursal de los anteriormente mencionados tienen prevalencia sobre el artículo 84 de la Ley 1116 del 2006, pues son normas especiales para cada caso especial, por lo cual, en principio, no sería viable acudir a la figura de validación judicial de acuerdos privados de reorganización, si las normas de cada trámite disponen una consecuencia distinta para cada trámite ${ }^{25}$. Así por ejemplo, las normas sobre modificación de acuerdos concordatarios, acuerdos de reestructuración y acuerdos de reorganización tendrían preferencia cuando alguien quisiera alegar la aplicación del artículo 84 de la Ley 1116 del 2006 y su decreto reglamentario para efectos de acreditar una modificación de uno de tales de dichos acuerdos. Lo mismo ocurriría si se quisiera celebrar un acuerdo de reorganización dentro de un trámite de liquidación judicial, pues la norma del artículo 66 de la Ley 1116 del 2006 ya regula tal supuesto, por lo cual la misma tendría aplicación preferente sobre las normas de la validación judicial de acuerdos privados.

El artículo 12 de la Ley 1116 del 2006 prevé la posibilidad de solicitar el inicio de un proceso de reorganización de varios deudores vinculados entre sí por su carácter de matrices, controlantes o subordinados, o cuyos capitales estén integrados mayoritariamente por las mismas personas jurídicas o naturales, sea que éstas obren directamente o por conducto de otras personas, o de patrimonios autónomos afectos a la realización de actividades empresariales que no tengan como efecto la personificación jurídica, independientemente de que la situación de control haya sido declarada o inscrita previamente o no en el registro mercantil.

De esta forma, el ordenamiento prevé la posibilidad de realizar una solicitud conjunta de validación de acuerdo extrajudicial de reorganización de un grupo de empresas, en donde todos los interesados expresan su consentimiento en el acuerdo de reorganización, cuando por las circunstancias propias del grupo, la insolvencia de uno de sus integrantes pueda afectar a los demás, cuando haya una integración económica entre los deudores integrantes del grupo, o ya sea porque haya una mezcla de bienes, control o propiedad en común y que sea determinante e importante en el momento de

25 Tales normas siguen rigiendo para los casos en curso al momento de entrada en vigencia de la Ley 1116 del 2006, como expresamente lo dispone el artículo 117 de la misma. 
formular y aprobar el respectivo acuerdo de reorganización. Esta previsión resulta útil en ciertas situaciones, como, por ejemplo, cuando la actividad comercial de los miembros de un grupo insolvente se encuentra estrechamente integrada y resulte más útil el trámite conjunto que coordinar los múltiples procedimientos paralelos.

La negociación del acuerdo de reorganización bajo el esquema previsto en el artículo 84 de la Ley 1116 del 2006 permitiría, a su vez, que en el acuerdo participara a título voluntario, y sin que sea considerada como deudora, una empresa solvente del grupo, si le conviene a sus intereses económicos y comerciales, y ello redunda en beneficio del grupo o sus miembros, sin que tal empresa se vea afectada por los efectos propios de los procesos formales de insolvencia ${ }^{26}$.

El acuerdo de reorganización, referido a un grupo de empresas, podría plantear problemas jurisdiccionales, si los distintos deudores están situados en diferentes lugares del país y si hay deudores sujetos a la competencia tanto del juez civil del circuito como de la Superintendencia de Sociedades, por lo que el parágrafo del artículo 23 del Decreto 1730 del 2009 dispuso que procederá la solicitud de validación de acuerdos de reorganización de varios deudores vinculados y que, en este caso, el proceso deberá iniciarse en la Superintendencia de Sociedades, de existir deudores sujetos a su competencia.

Serán acreedores del acuerdo aquellos que tengan acreencias patrimoniales ciertas a su favor causadas con anterioridad a la fecha en que se celebre el acuerdo y serán los acreedores incluidos en la calificación y graduación de acreencias y determinación de derechos de voto, con base en la cual se verificarán las mayorías para la celebración del acuerdo por parte del juez del concurso en el proceso de validación.

Sobre este punto vale la pena precisar que el artículo 22 del Decreto 1730 del 2009 dispuso que el deudor elaborará una calificación y graduación de créditos y determinación de derechos de voto, de conformidad con las reglas establecidas en la Ley 1116 del 2006, y un balance y un estado de inventario de activos y pasivos, con corte al último día del mes calendario inmediatamente anterior a la fecha de inicio de las negociaciones. Esta información será la que servirá de base al deudor para iniciar la negociación con los acreedores. Sin embargo, puede suceder que entre la fecha de inicio de las negociaciones, la celebración del acuerdo y la solicitud de validación, transcurra un gran espacio de tiempo en el cual se vayan generando obligaciones adicionales para el deudor, propias del giro ordinario de sus negocios, por lo que en el artículo 22 del mismo decreto se establece que se tendrán como acreedores del acuerdo

26 En materia de insolvencia de grupos y, en particular, sobre la posibilidad de la participación de los miembros solventes del grupo, ver Guía Legislativa de la CNUDMI sobre Insolvencia, Tercera Parte, Tratamiento de los grupos de empresas en situaciones de insolvencia, A/CN.9/WG.V/WP.90 del 31 de agosto del 2009. 
los titulares de acreencias patrimoniales ciertas, adquiridas hasta la fecha de celebración del acuerdo, y las posteriores tendrán el tratamiento propio de los gastos de administración, en aplicación de la regla contenida en el artículo 71 de la Ley 1116 del 2006, lo que obliga a concluir que una vez celebrado el acuerdo, el deudor deberá actualizar la información financiera, el estado de inventario de activos y pasivos, y la calificación y graduación de créditos, incluyendo las obligaciones causadas antes de la celebración de acuerdo, para cumplir con los requisitos de información dispuestos en el artículo 23 del Decreto 1730 del 2009, a efectos de surtir el trámite de validación. Algunas personas han criticado tales disposiciones, por cuanto argumentan que en la práctica ello puede traer algunos inconvenientes, pues al no existir una fecha de corte que sea la del inicio de las negociaciones, como se maneja en los acuerdos judiciales de reorganización, las acreencias y, en consecuencia, las mayorías decisorias, pueden variar durante la negociación del acuerdo, lo cual, argumentan, puede introducir algunos elementos distorsionadores en la misma. El tema queda abierto a discusión, pero es claro lo que el Decreto 1730 del 2009 dispone al respecto.

En lo atinente a la negociación del acuerdo, el deudor podrá en cualquier momento, y sin que sea necesaria la ocurrencia de los supuestos de admisibilidad $^{27}$ señalados en el artículo $9^{\circ}$ de la Ley 1116 del $2006^{28}$, iniciar negociaciones con los acreedores con el fin de celebrar un acuerdo extrajudicial de reorganización. Lo anterior significa que el deudor puede negociar un acuerdo extrajudicial de reorganización, aun no estando en cesación de pagos, aunque el inicio de la negociación con los acreedores prácticamente puede leerse por ellos como una "confesión del estado de cesación de pagos", con el riesgo que para el deudor representa la noticia anticipada de la insolvencia; lo anterior, obviamente, no descarta que el acuerdo se celebre si ya acaeció la cesación de pagos.

En la práctica, lo que pretende la norma es que para iniciar las negociaciones no se requieren los elementos que exteriorizan la cesación de pagos, como son la existencia de los incumplimientos o de las ejecuciones, con lo cual no se exige al deudor al momento del inicio de la negociación tener que justificar ante los acreedores el estado de cesación de pagos, sino que basta que exista la dificultad económica que de alguna manera se exterioriza por la celebración del acuerdo mismo, y que se pondrá de presente en la manifestación que hará el deudor en el propio acuerdo de conformidad con lo dispuesto en el parágrafo del artículo 25 del Decreto 1730 del 2009, el cual señala que el deudor debe, bajo la gravedad de juramento, manifestar en el acuerdo que se encuentra en alguno de los supuestos de que trata el artículo

27 Decreto 1730 del 2009. Artículo 20.

28 El artículo $9^{\circ}$ de la Ley 1116 del 2006 establece como supuestos de admisión a un procedimiento de insolvencia la existencia de una situación de cesación de pagos o de incapacidad de pago inminente. 
$9^{\circ}$ de la Ley 1116 del 2006 y el cumplimiento de los presupuestos indicados en el artículo 10 de dicha ley, relativos, básicamente, a no estar incurso en causal de disolución, estar cumpliendo con las obligaciones de comerciante, tener aprobado el cálculo actuarial si posee pasivos pensionales a cargo, y no tener a cargo obligaciones vencidas por retenciones de carácter obligatorio a favor de autoridades fiscales, por descuentos efectuados a los trabajadores o por aportes al Sistema de Seguridad Social Integral. En conclusión, pues, no es necesario demostrar la existencia de los supuestos de admisibilidad que sí hay que demostrar en un proceso judicial de reorganización, pero sí hay que afirmar bajo la gravedad del juramento que esos supuestos se dan, con lo cual el no cumplimiento real de los mismos podría acarrear las sanciones penales y civiles previstas para la realización de afirmaciones bajo la gravedad del juramento que no se ajustan a la realidad.

El inicio de las negociaciones deberá comunicarse a todos los acreedores externos del deudor, de acuerdo con lo dispuesto por el artículo 21 del Decreto 1730 del 2009. Sobre este punto hay que precisar que, a diferencia de lo que ocurre con los acuerdos judiciales de reorganización, para que un acuerdo privado pueda ser validado judicialmente, es necesario contar con el voto favorable del deudor, pues así lo exige el artículo 84 de la Ley 1116 del 2006, a diferencia de los acuerdos celebrados dentro del proceso concursal judicial, los cuales sólo exigen mayoría de los acreedores internos y externos, siendo posible que la mayoría se logre sólo con el voto proveniente de acreedores externos.

Con base en lo anterior, se podría entender que los acreedores internos, que son los socios de las sociedades o las personas que han hecho aportes cuando se trata de personas jurídicas distintas de sociedades, no tendrían ninguna participación en la figura de la validación judicial de acuerdos privados de reorganización, pues no se les debe notificar el inicio de las negociaciones y por cuanto el deudor actuaría por ellos. Sin embargo, no ha sido unánime la interpretación, en el entendido de que la regulación del Decreto 1730 del 2009 hace una remisión a las normas expresas sobre conformación de mayorías del artículo 31 de la Ley 1116 del 2006 y de calificación de acreencias y determinación de derechos de voto de la misma ley, normas en las cuales se tiene a los acreedores internos como parte de los acuerdos de reorganización. A favor de quienes sostienen que los acreedores internos no intervienen, existe el argumento según el cual el artículo 20 del Decreto 1730 del 2009 efectuaría la precisión que no hizo el artículo 84 de la Ley 1116 del 2006 de ser un acuerdo celebrado por los acreedores externos y el deudor.

Retomando el tema de la notificación del inicio de las negociaciones, recordamos que se dispone que deberá comunicarse a todos los acreedores externos del deudor, pero allí debe hacerse una precisión, pues es claro que debe notificarse a aquellos acreedores que figuren con acreencias ciertas a 
su favor a la fecha en que efectivamente se dé el inicio de las negociaciones, pero también habría que comunicar a aquellos acreedores que figuren con acreencias ciertas a su favor con obligaciones causadas entre la fecha de inicio de las negociaciones y la de celebración del acuerdo, para lo cual el deudor deberá indicar a todos aquellos con los que establezca vínculos contractuales que vayan a producir obligaciones patrimoniales a su cargo, que se encuentra adelantando negociaciones con sus acreedores. Esto es una consecuencia de haber incluido dentro del objeto del acuerdo privado que se someterá a validación judicial las obligaciones causadas durante la etapa de negociación del acuerdo.

Sin embargo, para salvar el escollo anteriormente mencionado, hay que tener en cuenta que de acuerdo con lo dispuesto por el artículo 21 del Decreto 1730 del 2009, podrá iniciarse la negociación del acuerdo solamente con los acreedores que tengan la mayoría necesaria para la celebración del mismo, sin necesidad de cumplir con el requisito de publicidad en ese sentido con respecto a los demás acreedores, pues dicha norma establece que se entenderá cumplido el requisito de publicidad, si se comunica la noticia sobre la existencia de las negociaciones a la totalidad de acreedores por lo menos con una antelación no menor de cinco (5) días hábiles a la firma del acuerdo.

En lo relativo a la celebración misma del acuerdo, debe entenderse que el acuerdo extrajudicial de reorganización es un convenio que se instrumenta en forma conjunta entre los acreedores y el deudor, y que se celebra por mayoría, en donde la manifestación de voluntad se hace a través de documento escrito firmado por el deudor y un número plural de acreedores que equivalga a la mayoría absoluta de los votos correspondientes a todos los acreedores, en los términos del artículo 31 de la Ley 1116 del 2006, y se impone a los ausentes o disidentes.

La mayoría se conforma respetando las clases de acreedores, que serán los i) acreedores laborales, ii) entidades públicas y las instituciones de seguridad social, iii) instituciones financieras nacionales y extranjeras y los supervisados por la Superintendencia Financiera, iv) acreedores internos ${ }^{29}$ y v) otros acreedores. La mayoría deberá obtenerse teniendo en cuenta las clases de acreedores, consiguiendo el voto favorable por lo menos de tres de las clases, de conformidad con lo establecido en la norma, salvo que el acuerdo se celebre con el voto favorable de un número plural de acreedores que representen, por lo menos, el setenta y cinco por ciento $(75 \%)$ de los votos. El acuerdo se entenderá celebrado, en la fecha en que se obtenga la mayoría exigida, de la cual quedará constancia expresa en el documento contentivo del acuerdo o en anexo del mismo, de conformidad con lo exigido en el artículo 22 del Decreto 1730 del 2009.

29 Si se tuvieran como partes del acuerdo, en una interpretación que hoy causa polémica. 
En cuanto se refiere al contenido del acuerdo de reorganización, aplican todas las disposiciones de la Ley 1116 del 2006 para los acuerdos celebrados dentro del proceso judicial de reorganización ${ }^{30}$. Para el caso de los acuerdos privados que van a ser sometidos a validación judicial, habría que agregar que el acuerdo debe contener la manifestación de voluntad de someter el mismo a un proceso de validación y, en este sentido, tiene razón de ser la facultad otorgada tanto para el deudor como para cualquiera de los acreedores de solicitar al juez del concurso la apertura de un proceso de validación. Adicionalmente, el acuerdo deberá contener la manifestación ${ }^{31}$ de que el deudor se encuentra en alguno de los supuestos de que trata el artículo $9^{\circ}$ de la Ley 1116 del 2006 y el cumplimiento de los presupuestos indicados en el artículo 10 de la misma.

Las estipulaciones del acuerdo deberán tener carácter general, es decir, deberán incluir todos los créditos ciertos que estén a cargo del deudor a la fecha de su celebración, así como todos los créditos litigiosos o contingentes.

Igualmente, en virtud de lo dispuesto por el artículo 25 del Decreto 1730 del 2009, los acuerdos privados que se sometan a validación judicial deberán cumplir los requisitos de contenido dispuestos en el artículo 34 de la Ley 1116 del 2006, el cual prevé:

- Que respetará para efectos del pago, la prelación, los privilegios y preferencias establecidas en la ley.

- Deberá incluir cláusulas que regulen la conformación y funciones de un comité de acreedores, y deberá pactar por lo menos una reunión anual de acreedores con el fin de hacer seguimiento al cumplimiento del mismo, dando aviso oportuno de su convocatoria al juez del concurso.

- Si el deudor tiene a cargo el pago de pasivos pensionales, deberá incluir el mecanismo de normalización de los mismos, el que deberá ser objeto de concepto previo favorable por parte del Ministerio de la Protección Social y la autorización de la Superintendencia que ejerza la inspección, vigilancia o control sobre el deudor. En cuanto a la obligación de normalización del pasivo pensional deberá cumplir con lo estipulado y, además, acreditando que está al día en mesadas pensionales, bonos y títulos pensionales exigibles y que tiene cálculo actuarial aprobado ${ }^{32}$.

Adicionalmente, el acuerdo no podrá incluir cláusulas abusivas para los acreedores o para el deudor (entendiendo por esto, el respeto a las preferencias de ley y a las reglas previstas para el acuerdo de reorganización, como

30 Entre esas disposiciones será también aplicable la contenida en el parágrafo del artículo 81 de la Ley 1116 del 2006, referida a la venta de la empresa como unidad de explotación económica, la cual responde a la necesidad de conservar la empresa viable, cuando se convenga que esta subsista aun en cabeza de alguien distinto del propio deudor.

31 Bajo la gravedad del juramento, según lo establecido en el parágrafo del artículo 25 del Decreto 1730 del 2009.

32 Decreto 1730 del 2009. Artículo 23, numeral 6. 
el consentimiento del acreedor para las daciones en pago, por ejemplo) ${ }^{33}$, ni contrarias a los preceptos legales (lo que se pretende es evitar que el acuerdo sea nulo por violación de norma imperativa) ${ }^{34}$, así como los créditos de la misma clase deberán recibir el mismo trato, para respetar el principio de igualdad de los procesos concursales (como forma de soportar en igual grado la pérdida derivada de la insolvencia del deudor) ${ }^{35}$, todo lo anterior en virtud de lo dispuesto por el artículo 84 de la Ley 1116 del 2006.

El mencionado artículo 84, en lo relativo a la "forma" de los acuerdos privados presentados a validación judicial, sólo menciona que deberán constar por escrito y se deberán tener en consideración las reglas que le sean aplicables, reglas que fueron determinadas en el Decreto 1730 del 2009 así: a) el acuerdo extrajudicial de reorganización es un acuerdo que se instrumenta en documento escrito y en forma conjunta entre los acreedores y el deudor ${ }^{36}, \mathrm{y} b$ ) se requiere adicionalmente la certificación de la firma, cuando el numeral $1^{\circ} \mathrm{del}$ artículo 23 del Decreto 1730 exige que el acuerdo deberá ser presentado con “(...) constancia de presentación personal de las partes (deudor y acreedores), acreditando la capacidad para suscribirlo y la existencia y representación legal, en el caso de las personas jurídicas" ${ }^{137}$.

La fecha de celebración del acuerdo será la fecha en que se obtenga la mayoría exigida, según lo dispuesto en el artículo 22 del Decreto 1730 del 2009. La ley no dispuso término, una vez celebrado, para la presentación del acuerdo a un proceso de validación judicial, por lo que el mismo tendrá validez entre las partes independientemente de su presentación ante el juez del concurso, si así también lo hubieran previsto deudor y acreedores.

Valdría la pena reflexionar si la ley permite que con posterioridad a la celebración del acuerdo o a la solicitud de validación, se agreguen nuevas conformidades o nuevos acreedores que aumenten o modifiquen las mayorías del acuerdo. Frente a la primera posibilidad, es decir, si una vez celebrado el acuerdo pueden agregarse nuevas conformidades, la respuesta siempre sería que sí, por cuanto basta con lograr la suscripción del acuerdo por parte de la mayoría absoluta de acreedores, para entenderlo celebrado, y las firmas o

33 Cfr. Juan José Rodríguez Espitia. Nuevo régimen de insolvencia. Pág. 590. Universidad Externado de Colombia. $1^{a}$ edición. Bogotá D.C. (2007).

34 Cfr. Juan José Rodríguez Espitia. Nuevo régimen de insolvencia. Pág. 590. Universidad Externado de Colombia. $1^{a}$ edición. Bogotá D.C. (2007).

35 Cfr. Juan José Rodríguez Espitia. Nuevo régimen de insolvencia. Pág. 589. Universidad Externado de Colombia. $1^{a}$ edición. Bogotá D.C. (2007).

36 El artículo 22 del Decreto 1730 del 2009 establece que “(...) el Acuerdo se tendrá por celebrado cuando el documento escrito que lo contenga sea firmado o suscrito por el deudor y un número plural de acreedores que equivalga a la mayoría absoluta de los votos correspondientes (...) En dicho documento o en anexo del mismo, deberá dejarse constancia expresa de la fecha en que se obtenga la mayoría exigida, que será la fecha de celebración del acuerdo".

37 Este requisito trata de asegurar “(...) un régimen transparente y fidedigno respecto del contenido de la negociación y del acuerdo”. (Julio C. Rivera, Horacio Roitman \& Daniel Vítolo. Concursos y quiebra. Ley 24.522. Pág. 97. Santa Fe: Rubinzal-Culzoni Editores. (1995). 
suscripciones recibidas con posterioridad que aumenten la mayoría exigida, siempre se recaudarán una vez celebrado el acuerdo.

Frente a la segunda posibilidad, es decir, si se pueden agregar conformidades una vez presentada la solicitud de validación, es pertinente considerar lo siguiente:

El artículo 23 del Decreto 1730 del 2009 dispuso que una vez celebrado el acuerdo, podría someterse al proceso de validación, solicitando la apertura del proceso, anexando el acuerdo, un balance, un estado de resultados, el estado de inventario de activos y pasivos, la calificación y graduación de créditos, entre otros; a su vez el artículo 24 del mismo decreto, referido al trámite de la solicitud, dispuso que presentada la misma, el juez del concurso verifica que se haya presentado la totalidad de documentos de que trata el artículo 23 mencionado, y dentro del término establecido en el artículo 14 de la Ley 1116 del 2009, deberá decretar la apertura del proceso de validación.

El artículo 14 de la Ley 1116 del 2006 dispone la admisión o rechazo de la solicitud de inicio del proceso. De considerarla ajustada a la ley, la aceptará dentro de los tres (3) días siguientes a su presentación; de no considerarla ajustada a la ley, por ejemplo, porque faltan documentos o porque el acuerdo no cuenta con la mayoría exigida por la ley, el juez del concurso requerirá mediante oficio al solicitante para que, dentro de los diez (10) días siguientes complete lo que le haga falta o rinda las explicaciones a que haya lugar, lo que en la práctica permitiría que con posterioridad a la solicitud de apertura del proceso de validación se agregaran nuevas conformidades o firmas al acuerdo.

En conclusión, se puede hablar de la posibilidad de completar requisitos durante el trámite, es decir, se podría reconocer validez a acuerdos celebrados en fecha posterior a la solicitud de validación del acuerdo, en una máxima manifestación de flexibilidad y "(...) esto podría interpretarse en que, una vez plasmado el acuerdo, el mismo se tornaría en un contrato de adhesión" 38 .

La finalidad del acuerdo debe ser coincidente con la finalidad de los procesos concursales, cual es la de proteger el crédito y fomentar la recuperación y conservación de la empresa como unidad de explotación económica y fuente generadora de empleo. En concreto, a través de la reorganización se pretende preservar empresas viables y normalizar sus relaciones comerciales y crediticias, mediante su reestructuración operacional, administrativa y de activos o pasivos. Adicionalmente, tales acuerdos también propenden a propiciar y proteger la buena fe en las relaciones comerciales y patrimoniales en general, y sancionar las conductas que le sean contrarias ${ }^{39}$. Se discute si existe la posibilidad de celebrar acuerdos que no busquen el salvamento o

38 Pablo C. Barbieri. Nuevo régimen de concursos y quiebras. Buenos Aires: Universidad de Buenos Aires, $2^{\text {a }}$ edición. (1997). Citado en Pablo Barbieri. Procesos concursales. pág. 331. Editorial Universidad. $1^{\mathrm{a}}$ edición. Buenos Aires. (1999).

39 Cfr. Ley 1116 del 2006. Artículo $1^{\circ}$. 
recuperación de la empresa sino que propendan a su liquidación; sobre el particular nos parece claro que el artículo 84 de la Ley 1116 del 2006 limita la posibilidad de aplicación de la figura de validación de acuerdos privados a aquellos que propendan a la reorganización del deudor insolvente, con lo cual quedarían excluidos de la misma los acuerdos liquidatorios o de adjudicación, los cuales podrán celebrarse bajo esquemas estrictamente privados o dentro de procesos concursales judiciales, de acuerdo con lo regulado al respecto por la Ley 1116 del 2006, pero no bajo el esquema previsto en el artículo 84 de la mencionada norma.

Por último, mencionamos que podrá pactarse en el acuerdo que, si no fuere objeto de autorización por parte del juez del concurso mediante el proceso de validación judicial, el mismo puede tener efectos vinculantes frente a quienes lo suscribieron o firmaron y que su incumplimiento sólo dará lugar a las acciones que genera cualquier incumplimiento contractual ${ }^{40}$.

\section{La validación judicial}

Está legitimada para solicitar el inicio de un proceso de validación judicial de un acuerdo privado cualquiera de las partes de dicho acuerdo, entendiendo por partes el deudor, por un lado, y alguno de sus acreedores que hubiera suscrito el acuerdo, por otro.

Sin embargo, existen unos requisitos formales que, en principio, sólo pueden ser cumplidos funcionalmente por el deudor; como por ejemplo, la presentación de los documentos anexos a la solicitud, relativos a información económica del deudor de que trata el artículo 23 del Decreto 1730 del 2009. Igual consecuencia podría predicarse de las publicaciones o comunicaciones de la negociación, que deben ser realizadas por el deudor, en virtud de lo dispuesto por el artículo 21 del Decreto 1730. Sin embargo, creemos que ello no es óbice para que, de no contarse con ciertos documentos o información de la necesaria para entender completa la solicitud de validación, el juez dé aplicación a los incisos cuarto y quinto del artículo 14 de la Ley 1116 del 2006, los cuales disponen: “(...) Si la solicitud es presentada por acreedores, la autoridad competente requerirá al deudor para que, dentro de los treinta (30) días siguientes, presente los documentos exigidos en la ley.

"Si la información allegada por el deudor no cumple dichos requisitos, se le requerirá para que dentro de los diez (10) días siguientes los allegue al proceso. Si este requerimiento no se cumple, se ordenará la apertura del proceso de liquidación judicial u ordenará la remoción inmediata de los administradores" ${ }^{\prime 4}$.

40 Decreto 1730 del 2009. Artículo 29, inciso $2^{\circ}$.

41 A este respecto, vale la pena advertir que las negociaciones referidas a la validación de acuerdos extrajudiciales de reorganización, no llevan aparejado el riesgo de la liquidación judicial del patri- 
Una de las particularidades introducidas por el Decreto 1730 del 2009 consiste en que también podrá solicitarse la apertura de un proceso de validación por el deudor, y aun sin haberse celebrado el acuerdo, cuando iniciadas las negociaciones del acuerdo privado, no haya sido posible llegar a su celebración por la amenaza de actos en contra del patrimonio del deudor que limiten la capacidad de negociación, como son, por ejemplo, la práctica de medidas cautelares o ejecución de garantías fiduciarias, lo que se traduce en que se podrá dar inicio al proceso de validación para que luego, en un plazo de veinte (20) días hábiles, el deudor allegue el acuerdo celebrado y todos los demás documentos exigidos por el artículo 23 del Decreto 1730 del $2009^{42}$. Si bien esta norma ha sido objeto de varias críticas, estimamos que es adecuada para asegurar que los fines de la figura puedan cumplirse. Además, para que no se utilice la misma de manera abusiva, el artículo 27 del Decreto 1730 del 2009 establece un límite para el efecto, al disponer que si iniciado un trámite de validación no hay lugar a la autorización del acuerdo, sólo se podrá intentar “(...) una nueva negociación de un acuerdo extrajudicial de reorganización" con lo cual se fija sólo otra oportunidad de acudir al mecanismo previsto por el artículo 84 de la Ley 1116 del 2006, de manera que la figura no se use de manera indefinida por los deudores que desean aprovecharse de los efectos del inicio de un proceso de validación para burlar a sus acreedores, alegando que dentro del plazo de veinte (20) días no fue posible celebrar el acuerdo privado y presentando indefinidamente nuevas solicitudes respaldadas en lo dispuesto por el parágrafo del artículo 21 del Decreto 1730.

De hecho, los efectos, tanto de la presentación de la solicitud de validación como de la admisión misma de tal solicitud, son similares a los que se producen con ocasión de un proceso judicial concursal de reorganización. Así, el artículo 26 del Decreto 1730 del 2009 dispone que a partir de la presentación de la solicitud de apertura del proceso de validación judicial, se generan los efectos previstos en el artículo 17 de la Ley 1116 del 2006, los cuales se concretan básicamente en la prohibición a los administradores para la adopción de reformas estatutarias, la constitución y ejecución de garantías o cauciones que recaigan sobre bienes propios del deudor, incluyendo fiducias mercantiles o encargos fiduciarios que tengan dicha finalidad, la prohibición de efectuar compensaciones, pagos, arreglos, desistimientos, allanamientos, terminaciones unilaterales o de mutuo acuerdo de procesos en curso, así como conciliaciones o transacciones de obligaciones a cargo del deudor, y la prohibición de efectuar enajenaciones de bienes u operaciones que no correspondan al giro ordinario de los negocios del deudor o que se lleven a cabo sin sujeción a las limitaciones estatutarias aplicables, incluyendo las fiducias mercantiles

monio del deudor insolvente.

42 Decreto 1730 del 2009. Artículo 21, parágrafo.

43 Decreto 1730 del 2009. Artículo 27. 
y los encargos fiduciarios que tengan esa finalidad o encomienden o faculten al fiduciario en tal sentido, salvo que exista autorización previa, expresa y precisa del juez del concurso.

Por su parte, a partir del momento en que la solicitud de validación judicial de un acuerdo privado sea admitida, se generarán los efectos propios del inicio del proceso de reorganización, con excepción del concerniente a la remisión de los procesos de ejecución, los que serán suspendidos. Dichos efectos se regulan en los artículos 20 a 23 de la Ley 1116 del 2006, siendo el más importante de ellos el consistente en que a partir de la fecha de inicio del proceso, no podrá admitirse ni continuarse demanda de ejecución o cualquier otro proceso de cobro en contra del deudor, así como de procesos de restitución de tenencia sobre bienes muebles o inmuebles con los que el deudor desarrolle su objeto social y que tenga a título de arrendamiento o leasing, sin perjuicio de las particularidades del caso y de otros efectos como la suspensión de la causal de disolución por pérdidas y la continuidad de contratos, entre otros.

El proceso de validación es de competencia del juez del concurso, que será la Superintendencia de Sociedades, en uso de facultades jurisdiccionales, en caso de que el deudor sea una sociedad, una empresa unipersonal, una sucursal de sociedad extranjera o una persona natural comerciante a prevención. El juez competente será el juez civil del circuito del domicilio principal del deudor, en los demás casos de sujetos no excluidos del proceso.

El objeto del proceso de validación no es otro que verificar la legalidad del acuerdo, siendo el artículo 84 de la Ley 1116 del 2006 más específico que cuando la ley describe la labor del juez del concurso en un proceso judicial de reorganización, por cuanto exige que dentro de la revisión de legalidad de un acuerdo privado presentado a validación judicial expresamente se verifique que: i) el acuerdo cuenta con los porcentajes requeridos para configurar la mayoría; ii) que cumplió el requisito de publicidad frente a todos los acreedores; iii) respecto del contenido del acuerdo, que éste otorga los mismos derechos a todos los acreedores de una misma clase, no incluye cláusulas ilegales o abusivas y cumple con los preceptos legales.

Las etapas del proceso pueden dividirse en: i) presentación de la solicitud; ii) admisión, inadmisión o rechazo de la solicitud; iii) traslado de la solicitud admitida, y iv) autorización o no autorización del acuerdo. Pasamos a explicar sucintamente cada una de ellas.

La presentación de la solicitud debe cumplir los requisitos formales ${ }^{44}$ establecidos en el artículo 23 del Decreto 1730 del 2009, consistentes en presentación: del acuerdo; del balance general que sirvió de base para la elaboración de la calificación y graduación y determinación de derechos de

44 Los cuales no aplican en el caso de amenaza al patrimonio del deudor, regulado en el parágrafo del artículo 21 del Decreto 1730 del 2009. 
voto; del estado de resultados; del estado de inventario de activos y pasivos con fecha de corte al último día del mes calendario inmediatamente anterior a la fecha de inicio de las negociaciones, todos los anteriores suscritos por el deudor, contador público y revisor fiscal si lo hubiere; de la calificación y graduación de acreencias y determinación de derechos de voto, con los acreedores que tengan acreencias patrimoniales ciertas a su favor causadas con anterioridad a la fecha en que se celebre el acuerdo, siguiendo las reglas previstas en la Ley 1116 del $2006^{45}$; de prueba de las comunicaciones a los acreedores; de certificación en la que se indiquen las diferencias o controversias de las que el deudor tenga conocimiento que existan con relación a la naturaleza, cuantía y voto de los acreedores; y de certificación de que el deudor se encuentra al día en mesadas, bonos y títulos pensionales y que tiene cálculo actuarial aprobado con concepto previo favorable del Ministerio de la Protección Social sobre la normalización del pasivo pensional, si el deudor tiene obligaciones pensionales a cargo.

La solicitud puede ser admitida, inadmitida o rechazada, en los mismos términos del Código de Procedimiento Civil. La inadmisión y el rechazo no causan efecto distinto que el de la necesidad de subsanar la solicitud o de formular una nueva. La admisión da lugar a la apertura del proceso de validación judicial, para lo cual se tendrán en cuenta las normas de notificación previstas en la Ley 1116 del 2006 para los procesos judiciales de reorganización, destacándose en el auto de apertura la orden de traslado de los documentos presentados con la solicitud, la convocatoria a una audiencia de validación del acuerdo, la orden al deudor para que comunique a los jueces y autoridades que estén conociendo de procesos en su contra sobre la suspensión de los procesos mientras se valida el acuerdo, y la orden de librar oficio a la cámara de comercio con competencia en el domicilio del deudor para que se inscriba la noticia en el registro mercantil, de conformidad con lo dispuesto en el artículo 24 del Decreto 1730 del 2009.

Durante el término de traslado, que es de diez (10) días, únicamente los acreedores que no suscribieron el acuerdo privado pueden presentar observaciones al acuerdo celebrado u objeciones a la calificación y graduación de créditos y a la determinación de derechos de voto. De presentarse objeciones, se seguirá el procedimiento establecido para el efecto en los artículos 29 y 30 de la Ley 1116 del 2006, es decir, se dará traslado de las mismas por un término de cinco (5) días, se buscará la conciliación de las mismas en los diez (10) días subsiguientes y, si ello no es posible, entrará el juez de validación a decidirlas en audiencia que convocará para el efecto, previa práctica de pruebas, si ello fuere necesario. Por su parte, si se presentaren observaciones contra el acuerdo celebrado, las mismas deberán ser tenidas en cuenta por

45 Decreto 1730 del 2009. Artículo 22. 
el juez de validación para efectos de determinar en la audiencia convocada, si autoriza o no el acuerdo. Dejamos anotado que el Decreto 1730 del 2009, en su artículo 24, no previó la posibilidad de objeciones contra el inventario de bienes allegado con la solicitud de validación; aunque ello fue regulado así, tal posibilidad existe para quienes quieran interponer objeciones contra tal inventario, por existir disposición sobre el asunto en el artículo 29 de la Ley 1116 del 2006, al cual remite el numeral $1^{\circ}$ del artículo 24 del Decreto 1730 del 2009.

Si no hubo objeciones ni observaciones o, si las hubo, una vez resueltas las mismas, se celebrará audiencia en la cual se comunicará la decisión del juez y se dará lugar a la autorización o no del acuerdo privado sometido a validación judicial, previo estudio del cumplimiento de todos los requisitos que exige el artículo 84 de la Ley 1116 del 2006 y el Decreto 1730 del 2009 ya mencionados. La autorización otorgará los efectos propios de un acuerdo de reorganización celebrado en el marco de un proceso judicial de reorganización, destacándose el de vinculación con respecto a acreedores que no lo hayan votado, bien sea por ser ausentes o disidentes, además del archivo de los procesos de ejecución que se adelantaban en contra del deudor y el consiguiente levantamiento de las medidas cautelares practicadas, como lo regula el artículo 28 del Decreto 1730 del 2009. Adicionalmente, si hacia futuro el acuerdo autorizado fuere incumplido, habrá lugar a la apertura de un proceso de liquidación judicial, como ocurre cuando se incumple un acuerdo de reorganización celebrado dentro de un proceso judicial de reorganización.

En caso de que el acuerdo no fuere autorizado para su validación, se procederá conforme lo prevé el artículo 35 de la Ley 1116 del 2006, es decir, se concederá por una sola vez un plazo de ocho (8) días para que el acuerdo sea corregido y aprobado por los acreedores, de conformidad con las observaciones hechas por el juez de validación. Si el nuevo acuerdo es presentado dentro del término, el juez entrará a estudiar si lo autoriza o no. Si el acuerdo es autorizado, ya conocemos los efectos que se producen, pero si el acuerdo no es presentado dentro del término anteriormente mencionado o si no fuere finalmente autorizado, el proceso de validación terminará y se informará sobre ello a la Cámara de comercio y autoridades que hayan sido previamente notificadas sobre la apertura del proceso.

Una de las consecuencias más importantes de la no autorización es que no se sigue el inicio de un proceso de liquidación del patrimonio del deudor, como ocurre cuando no se confirma un acuerdo de reorganización celebrado dentro de un proceso judicial de reorganización, sino que el deudor podrá seguir actuando de manera normal e incluso podrá intentar una nueva negociación y validación de un acuerdo privado o solicitar la admisión a un proceso judicial de reorganización. Como ya se expuso previamente, la no autorización del acuerdo implicará que el acuerdo privado “(...) cesará en 
sus efectos frente a quienes lo suscribieron, salvo que en el mismo se hubiere dispuesto lo contrario, en cuyo caso sólo tendrá efectos vinculantes en relación con quienes lo hubieren suscrito o firmado y su incumplimiento sólo dará lugar a las acciones que genera cualquier incumplimiento contractual" 46 . Esto es importante, por cuanto un acuerdo privado celebrado con fines de validación judicial perderá todos sus efectos vinculantes si no es objeto de autorización por parte del juez de validación, lo cual no ocurre con los acuerdos estrictamente privados, que siguen rigiéndose por los principios tradicionales de derecho privado, en particular, de ser fuente de obligaciones y ley para las partes ${ }^{47}$. El tema no deja de ser controversial, si se tiene en cuenta que en la práctica no siempre es clara la línea que delimita cuándo un acuerdo privado se celebra con fines de validación judicial y cuándo no, por lo cual deberán los asesores tanto de deudores como de acreedores ser muy cuidadosos al respecto, para no llegar a malentendidos.

\section{UN EJEMPLO DE LA "PRIVATIZACIÓN" DEL DERECHO CONCURSAL}

La finalidad del derecho concursal es la creación de un marco jurídico eficiente para regular la situación de los deudores que se encuentran en dificultades de cumplir las obligaciones a su cargo ${ }^{48}$. El derecho de la insolvencia ${ }^{49}$ está indisolublemente ligado a fenómenos de carácter económico, pues el daño y la devastación que produce un evento de insolvencia afectan al individuo en particular, a la empresa y hasta al Estado mismo, lo cual ha determinado un impacto sustancial en la normatividad comercial y financiera de la mayoría de los países del mundo ${ }^{50}$. El derecho de insolvencia no es simplemente la regulación de un procedimiento, sino la implementación de una política de Estado, teniendo en cuenta que tiene un efecto directo en el desarrollo económico,

46 Decreto 1730 del 2009. Artículo 29.

47 El artículo 30 del Decreto 1730 del 2009 excluye de la aplicación de dicho decreto y del artículo 84 de la Ley 1116 del 2006 a todos aquellos acuerdos privados que se celebren sin vocación de ser sometidos a validación judicial.

48 Cfr. JuAn José Rodríguez Espitia. Nuevo régimen de insolvencia. págs. 31-33. Universidad Externado de Colombia. $1^{a}$ edición. Bogotá D.C. (2007).

49 La Ley 1116 del 2006 por primera vez habla de insolvencia en la legislación colombiana. Cuando un deudor se ve en la imposibilidad de pagar sus deudas y cumplir con sus obligaciones, la mayoría de los ordenamientos jurídicos prevén mecanismos legales para satisfacer colectivamente las reclamaciones pendientes, afectando a su pago todos los bienes del deudor y vinculando a todos los acreedores del mismo, abogando por el tratamiento en condiciones de igualdad para los acreedores que se encuentren bajo supuestos similares. A este conjunto de normas se les denomina, en general, derecho concursal o de insolvencia.

50 Cfr. Diana lucía Talero Castro. "Predictibilidad, un elemento esencial de un régimen de insolvencia moderno”. En Empresas Colombianas: Actualidady Perspectivas. Pág. 169. Superintendencia de Sociedades. $1^{\mathrm{a}}$ edición. Bogotá D.C. (2009). 
consecuencias reales, costos reales y no consiste simplemente en establecer un sistema en que un deudor paga y un acreedor es pagado o no lo es.

La evolución del derecho concursal ha procurado resolver de manera colectiva la protección de algunos derechos particulares envueltos en los procesos. En la tarea de crear esta regulación, el Estado ha procurado que los regímenes de insolvencia creen escenarios de negociación entre diversos intereses, en donde se busque la conjugación de dichos intereses, pero en los cuales siempre terminará primando uno sobre los demás ${ }^{51}$. A través de la evolución del derecho concursal, ha ido identificándose como interés tutelado el de la mayoría, pues poco a poco la solución contractual se ha edificado en un contrato de mayorías. Así se ha avanzado de manera que la solución a la insolvencia, no obstante se tramite un proceso de recuperación o de liquidación, se encuentre a través de acuerdos, convenios o contratos ${ }^{52}$. En el proceso de reorganización la finalidad será la de lograr un "acuerdo" de reorganización y en la liquidación será la de lograr un "acuerdo" de adjudicación.

En consecuencia, la autonomía privada, entendida como "(...) la delegación que el legislador hace en los particulares de la atribución o poder que tiene de regular las relaciones sociales, delegación que estos ejercen mediante el otorgamiento de actos o negocios jurídicos" ${ }^{n 3}$, es actualmente uno de los ejes

51 Cfr. Jesús María Sanguino Sánchez. Cesación de pagos en los procedimientos concursales. Págs. 9-12. Ediciones Librería del Profesional. Bogotá D.C. (1982). $1^{\text {a }}$ edición.

52 Podría argumentarse, incluso, que tal naturaleza contractual de los acuerdos concordatarios siempre ha existido, pues desde mucho tiempo atrás se han sostenido diversas tesis sobre la naturaleza contractualista de los concordatos. Por ejemplo, en el ámbito nacional se cita a Guillermo OsPinA FERNÁNDEZ al respecto, quien afirmaba que los concordatos eran contratos colectivos, por oposición a los contratos relativos, pues constituyen una excepción al principio de la relatividad de los contratos, ya que de ellos resultan derechos y obligaciones para personas que, ni directamente ni representadas por otras, han intervenido en su celebración (Cfr. Guillermo OsPina Fernández \& EduARdo OsPina Acosta. Teoría general del contrato y de los demás actos o negocios jurídicos. Págs. 70-71. Editorial Temis S.A. Cuarta edición actualizada. Bogotá D.C. (1994)), así como lo expuesto por OsPinA FeRNÁNDEZ sobre la índole transaccional del concordato, lo cual lo sujetaría al régimen del contrato de transacción (Cfr. Guillermo Ospina Fernández. Régimen general de las obligaciones. Pág. 80. Editorial Temis S.A. Bogotá D.C. (1976). Citado por Darío Londoño SALDARRIAGa. El concordato preventivo. Págs. 29-30. Editorial Temis, S.C.A. $1^{a}$ edición. Bogotá D.C. (1982)). Sin embargo, somos partidarios de lo expuesto por el mencionado Londoño SAldarriaga, en el sentido que "(...) Devanarse los sesos buscándole al concordato parecidos acomodaticios con las instituciones existentes, y tratar, por todos los medios posibles, de encajarlo en una de ellas, es desconocer el carácter progresivo del derecho y creerlo un orden perfecto. (...) Así las cosas, consideramos el concordato como un proceso autónomo, entendiendo por tal, una serie de actuaciones concatenadas y destinadas a regular una situación jurídica. Es autónomo porque la misma ley señala, con prescindencia de cualquier otro, los cauces dentro de los cuales se debe mover, es decir, está dotado de un procedimiento que le es propio. Es unitario, porque todos sus actos están íntimamente relacionados entre sí y la coordinación entre unos y otros es tal que forman un solo cuerpo. Y tratar de desligarlos es desnaturalizar el proceso y hacerle perder su unidad. Es colectivo, porque a él están llamados a concurrir todos los acreedores sin excepción alguna, pero sin la pretensión que acompaña al ejecutante contra el ejecutado, ya que no estamos en presencia de un proceso de esta naturaleza". (DARío Londoño SaLdarRiaga. El concordato preventivo. Pág. 31. Editorial Temis. S.C.A. 1a edición. Bogotá D.C. (1982)).

53 Guillermo Ospina Fernández y Eduardo Ospina Acosta. Teoría general del contrato y de los demás actos o negocios jurídicos. Pág. 6. Editorial Temis S.A. Cuarta edición actualizada. Bogotá D.C. (1994). 
fundamentales del derecho comercial ${ }^{54} \mathrm{y}$, en particular, del derecho concursa ${ }^{55}$, lo que nos hemos permitido denominar como "privatización" del derecho concursal $^{56}$. Si bien la autonomía privada vivió una época de profunda crisis, como consecuencia de los desafueros en que incurrieron los particulares que abusaron de su situación de poder y que llevaron a una situación de excesiva intervención del Estado en las actividades de los particulares ${ }^{57}$, hoy en día tal principio vive un reverdecimiento tal y como lo expone el profesor MUÑOZ LAVERDE cuando afirma: "(...) Lo que por ahora deseo resaltar es que sin perjuicio de los naturales cambios y ajustes que determinadas y puntuales normas demandan, nuestro Código Civil constituye un sistema de principios e instituciones producto de siglos de evolución jurídica, que, con la debida interpretación, acompasada con la realidad actual, resultan vitales para la coherencia de las relaciones jurídicas entre particulares. Mucho más que normas individualmente consideradas, lo que debe preservarse de las instituciones clásicas, recogidas en el Código Civil, son tales principios, algunos eternos, que orientan con claridad y precisión y que, a su turno, son base para el entendimiento y construcción de novedosas figuras que el tráfico moderno impone.

“(...) Ahora bien, con apoyo en la Constitución de 1991, la Corte Constitucional ha introducido ajustes a algunas disposiciones del Código Civil como son, entre otras, las que regulaba de manera diferencial la edad y el domicilio para contraer matrimonio; la que establecía la incapacidad absoluta del sordomudo que no puede darse a entender por escrito; la que disponía la inhabilidad especial para la celebración del contrato de compraventa respecto de cónyuges no separados de cuerpos; la que señalaba el orden de preferencia dentro de los créditos de primera clase; la que fijaba como domicilio de los trabajadores el de sus empleadores; etc.

54 Sostiene Efraín Hugo Richard que: “(...) La "eficiencia jurídica” la acercamos no sólo a la seguridad jurídica, o sea, a la efectivización del derecho sustantivo a través del acceso a la jurisdicción, sino también a la velocidad de ese restablecimiento que implica que el daño sea reparado en el menor tiempo posible. Es de práctica en el comercio internacional que las partes inserten cláusulas especiales para determinar, conforme a la autonomía de la voluntad, cuál será el derecho aplicable para regir su relación, en particular los conflictos, eligiendo el más adecuado a sus fines, e inclusive determinando el juez competente. (...) Creatividad, complejidad, escape al marco normativo, internacionalización, autoejecución de los contratos, son algunas de las pautas que guían la conducta de los agentes económicos, generando un nuevo microclima, que incluso impulsa la política". (EFraín Hugo RichaRd. Insolvencia societaria. Pág. 39. Lexis Nexis Argentina S.A. $1^{\text {a }}$ edición. Buenos Aires. (2007)).

55 Cfr. Juan José Rodríguez Espitia. Nuevo régimen de insolvencia. Págs. 586-587. Universidad Externado de Colombia. $1^{\text {a }}$ Edición. Bogotá D.C. (2007).

56 También llamado por la doctrina argentina "privatismo jurídico”. Cfr. Pablo C. Barbieri Procesos Concursales. Pág. 328. Editorial Universidad. $1^{a}$ edición. Buenos Aires. (1999).

57 Cfr. Guillermo Ospina Fernández \& Eduardo Ospina Acosta. Teoría general del contrato y de los demás actos o negocios jurídicos. Pág. 16. Editorial Temis S.A. Cuarta edición actualizada. Bogotá D.C. (1994). 
"Pero, mientras ciertas y puntuales normas legales han sido, por fuerza de las circunstancias, objeto de ajustes, otras, como lo es la que consagra el postulado de autonomía privada, permanecen incólumes"

En efecto, en una materia que a primera vista parecería más de índole procesal que sustancial, como es la insolvencia empresarial, se observa cada vez más la preponderancia de la autonomía de la voluntad privada como principio rector de los regímenes adoptados a nivel nacional y mundial para tratar el fenómeno económico de la insolvencia nacional y transfronteriza, pues se ha tomado conciencia de que la intervención del Estado en este tipo de situaciones sólo debe producirse para dar solución a controversias que no puedan ser decididas directamente por las partes interesadas, ya que son los afectados por la situación de insolvencia los que están en la capacidad y la obligación de decidir qué hacer ante el no pago o incumplimiento de su crédito y determinar si pueden brindarle o no elementos al deudor insolvente, que permitan su reactivación y eventual atención de las acreencias en un plazo más largo que el originalmente pactado ${ }^{59}$. Así, el antecedente inmediato en

58 Sergio Muñoz Laverde. El postulado de la autonomía privada y sus límites frente al constitucionalismo colombiano contemporáneo. Ponencia en el Congreso Internacional "Neoconstitucionalismo y derecho privado. El debate", realizado los días 13, 14 y 15 de septiembre del 2006 por la Facultad de Ciencias Jurídicas de la Pontificia Universidad Javeriana. Págs. 251-252. Biblioteca Jurídica Diké. $1^{\mathrm{a}}$ edición. Bogotá D.C. (2008).

59 Nos parece indispensable transcribir el aparte respectivo de la Exposición de motivos de la Ley 550 de 1999, por su valor ilustrador sobre el fenómeno de la "privatización" del derecho concursal. La mencionada exposición rezaba: “(...) El régimen legal vigente está inspirado en la concepción procesal de los mecanismos concursales, cuyo origen último obedece a la circunstancia de que la quiebra tradicional estaba acompañada de un severo régimen de sanciones personales para el comerciante fallido, a quien en un principio se presumía como defraudador, por lo cual el Estado se interesaba en la represión de la ilicitud de la quiebra.

"Paulatinamente se extendió la distinción entre los deudores de buena y mala fe, para someter a cada uno de ellos a un proceso distinto, hasta llegar en la actualidad a la separación de los efectos personales y patrimoniales de un concurso aplicable a comerciantes y no comerciantes, reflejo de la distinción entre empresario y empresa que obedece a la preocupación de interés público en la conservación de esta última como fuente de empleo y de riqueza.

"Sin embargo, hay que precisar que la trascendencia constitucional de la empresa como base del desarrollo, que permite la imposición de obligaciones legales en atención a su función social, no implica que el tratamiento de su crisis tenga que afrontarse a través de procesos de carácter jurisdiccional, como lo es el concordato actualmente vigente, confiado por regla general a la Superintendencia de Sociedades, con base en la previsión del artículo 116 de la Constitución Política.

"Por el contrario, y en forma consistente con la tendencia contemporánea a la desjudicialización de la solución de los conflictos entre particulares, en esta materia y en las actuales circunstancias de crisis empresarial generalizada, renace el interés en la antigua polémica de la doctrina jurídica comparada acerca de la naturaleza contractual o procesal del concordato.

"Es importante tener en cuenta que en nuestro país, y en la misma línea del derogado decreto 350 de 1989 , en la Ley 222 de 1995 se asignó a la Superintendencia de Sociedades la competencia que actualmente ejerce en materia de procesos concursales concordatarios y liquidatorios, pues, según se dijo en la exposición de motivos, "se ha considerado oportuno buscar que la legislación de procesos concursales contribuya a la descongestión de despachos judiciales aprovechando la infraestructura y la experiencia que sobre el particular tiene la administración y adicionalmente considerando que este tipo de procesos son muchas veces más económicos que jurídicos lo que facilita un trámite ante una autoridad administrativa que ejerza funciones jurisdiccionales". 
Colombia de la validación judicial de acuerdos privados, objeto de estudio de este artículo, puede encontrarse en los acuerdos de reestructuración de la Ley 550 de 1999. Como ya se expuso, la expedición de tal ley estuvo marcada por un matiz claramente contractualista, reflejado en que en la exposición de motivos de tal ley ya se hacía mención a los acuerdos preventivos extrajudiciales como una de las soluciones que ofrece el derecho concursal. En efecto, según lo expuesto por el legislador en ese momento, se mencionaba como uno de los criterios orientadores del mecanismo de los acuerdos de reestructuración, la naturaleza contractual y no procesal del mismo.

Tal "privatización" del derecho concursal también puede hacerse evidente en nuestro ordenamiento jurídico en la figura de los acuerdos de adjudicación de la Ley 1116 del 2006, a través de los cuales se persigue que como consecuencia del fracaso de un proceso judicial de reorganización o dentro del marco de un proceso de liquidación del patrimonio de un deudor, sean los acreedores

\footnotetext{
"Sin desconocer que el trámite concordatario en manos de la Superintendencia de Sociedades se adelanta en forma más ágil que mediante la justicia ordinaria, en el presente proyecto -en el cual, por cierto, no se deroga, sino que simplemente se suspende el actual régimen concursal-se parte de la base de que la crisis empresarial generalizada debe afrontarse con instrumentos que no tengan la naturaleza de procesos jurisdiccionales, es decir, que debe consagrarse la desjudicialización de los mecanismos de recuperación empresarial; y como alternativa frente al concordato vigente, se propone un acuerdo entre los acreedores de la empresa que es una convención colectiva vinculante para el empresario y todos los acreedores.

"Se le otorga así a los acuerdos que se celebran diariamente la indispensable y reclamada eficacia obligatoria frente a disidentes y ausentes, excepción a la relatividad de las convenciones que perfectamente se puede establecer por ley, si en la negociación y celebración del acuerdo se observa un marco de publicidad y legalidad previamente determinado por la propia ley.

"Se considera, entonces, que la previsión legal de determinados efectos, como lo es dicha obligatoriedad, como consecuencias normativas automáticas de acuerdos que reúnan determinadas características, puede reemplazar, con ventaja, la homologación o aprobación de naturaleza jurisdiccional, en especial dada la agilidad requerida para afrontar la crisis.

"Y en atención, precisamente, a que "este tipo de procesos son muchas veces más económicos que jurídicos", como se puso de relieve en la exposición de motivos del proyecto que condujo a la expedición de la Ley 222 de 1995, se da un paso adicional consistente en la promoción de los acuerdos a través de todas las Superintendencias distintas de la Bancaria, y de la de Economía Solidaria -en tratándose de actividades financieras y de ahorro y crédito- y no solamente de la de Sociedades, y de las Cámaras de Comercio, herederas de las corporaciones de mercaderes y de los consulados que se encargaban de las causas mercantiles en los orígenes del derecho comercial; promoción que tales entidades no adelantarán directamente, pues recurrirán a personas especialmente calificadas para contribuir al éxito de la negociación entre las partes, función que, se repite, es más económica que jurídica, y cuyas características se ha considerado que pueden acompañarse de una función como la del amigable componedor.

"Debe añadirse que la cuestión no es nueva en el país. A partir de 1982 y hasta la expedición del decreto 350 de 1989, se estudió en diversos foros académicos y empresariales la posibilidad de consagrar legislativamente en estas materias un "convenio privado", esto es, un acuerdo extrajudicial con efectos vinculantes entre el deudor y sus acreedores, aunque finalmente se acogió la propuesta publicista y judicial de la Superintendencia de Sociedades plasmada en dicho decreto.

"Este proyecto recupera el criterio contractualista y extrajudicial de las propuestas de entonces, y que no es extraño desde un punto de vista comparado, incluso tratándose de instrumentos diseñados para crisis de empresarios aislados. Lo confirman, entre otros casos, el acuerdo amigable de la ley francesa 84-148 del 1 de marzo de 1994 y el acuerdo preventivo extrajudicial de la ley argentina de Concursos y Quiebra 24.522 de 1995".
} 
los que en primer término, y en ejercicio de la autonomía privada, decidan cómo se adjudican tales bienes y, sólo si tal acuerdo no es posible, será el juez del concurso el que entre a suplir a los acreedores en tal decisión ${ }^{60}$. Esta figura ha sido objeto de no pocas críticas, pero a pesar de ello, se constituye en un claro reflejo de la tendencia que impera en nuestro derecho concursal ${ }^{61}$.

A nivel internacional también puede observarse el fenómeno de la "privatización" del derecho concursal, no sólo en los derechos internos de cada país, sino en ámbitos como el de la insolvencia transfronteriza, fenómeno que se presenta cuando se ven involucradas personas provenientes o bienes ubicados en más de un país ${ }^{62}$. En efecto, aunque existe una ley modelo de la CNUDMI sobre la insolvencia transfronteriza, la misma nunca nos va a resolver las inquietudes que se presentan de fondo sobre cómo afrontar los diversos conflictos de intereses que surgen entre deudor y acreedores, acreedores entre sí, socios, etc., en el marco de los procesos de insolvencia, pues para el efecto la ley modelo dispone que el ordenamiento jurídico del país donde se adelanta el proceso dentro del cual se está suscitando la controversia, es el encargado de solucionar la situación, y si eventualmente se presentare conflicto entre los procesos de distintos países, la ley modelo llama a la cooperación y la colaboración como mecanismos de solución de los conflictos y otorga amplio margen de maniobra a los países para apartarse de la ley modelo y darle prelación a su proceso local, si así llegare a considerarse necesario. Inclusive, la misma CNUDMI es consciente de los problemas de su ley modelo sobre insolvencia transfronteriza, lo cual la ha llevado a trabajar en documentos que expliquen en mayor detalle cómo puede llevarse a cabo tal cooperación y coordinación, de lo cual es reflejo el documento "Guía de prácticas de la CNUDMI sobre cooperación en la insolvencia transfronteriza" ("la Guía de prácticas") sobre cooperación, comunicación y coordinación en procedimientos de insolvencia transfronteriza ${ }^{63}$. Dicho documento da guías a los Estados sobre cuáles son las formas de cooperación que pueden utilizar y profundiza sobre una figura denominada acuerdos transfronterizos (también llamados contratos de administración de la insolvencia, acuerdos de cooperación y avenencia o memorandos de entendimiento), que ha venido siendo utilizada recientemente para dar solución a los problemas prácticos que no resuelven las normas sobre insolvencia transfronteriza, y cuyo tratamiento amerita un estudio profundo, el cual no realizamos en el presente artículo;

60 Cfr. Ley 1116 del 2006. Artículos 37 y 57.

61 Cfr. Álvaro Isaza Upegui \& Álvaro Londoño Restrepo. Comentarios al régimen de insolvencia empresarial - Ley 1116 del 2006. Págs. 313-331. Legis Editores S.A. $2^{\mathrm{a}}$ edición. Bogotá D.C. (2008).

62 Cfr. Comisión de las Naciones Unidas para el derecho mercantil internacional (CNUDMI). Presentación de la ley modelo de la CNUDMI sobre la insolvencia transfronteriza con la guía para su incorporación al derecho interno. En http://www.uncitral.org/uncitral/es/uncitral_texts/ insolvency/1997Model.html.

63 Adoptada por la CNUDMI el $1^{\circ}$ de julio del 2009. 
sin embargo, es claro que en dichos acuerdos transfronterizos también prima la autonomía privada, pues se prevé que gran parte de la solución a los problemas de insolvencia recae en los acuerdos que al respecto puedan celebrar las partes directamente afectadas ${ }^{64}$.

Una vez revisado de manera muy general el panorama de la "privatización" del derecho concursal, y concentrándonos en el objeto de estudio del presente escrito, que no es otro que el escenario no formal de la insolvencia, donde también la solución se logra a través de la negociación de un contrato denominado "acuerdo extrajudicial de reorganización", encontramos que el mismo no es otro que un contrato de mayorías que también resuelve la insolvencia del deudor, en un proceso no judicial de negociación, con una respuesta más temprana y activa de los acreedores y menor confrontación, donde prima la autonomía privada sobre la intervención del Estado.

Así, la solución contractual a la insolvencia, tanto en los procesos formales como informales de insolvencia, marca una realidad y tendencia irreversible hacia lo que se ha venido denominando la "privatización" del derecho concursal, con una característica adicional y propia exclusivamente de este régimen informal de insolvencia, consistente en que, si bien la validez del contrato se logra por haberse logrado la mayoría prescrita en la ley en cuanto a votos y categorías de acreedores, con lo cual se convierte en vinculante para las partes que consintieron en él, la ley prevé una vía judicial para permitir que el acuerdo sea vinculante también para los acreedores disconformes o ausentes ${ }^{65}$.

Si bien podría presentar críticas a la evolución hacia una estructura privatística de la ley de insolvencia, sosteniéndose que el control judicial debiera ser preservado para la determinación de lo que se paga y la forma en la que se hace, "(...) esta objeción pierde de vista, en parte, que la resignación del rol preponderante del juez en la solución de las crisis patrimoniales puede justificarse en orden a las urgencias que la caracterizan; éstas suelen ser usual y eficazmente respondidas, y de mejor manera en el entendimiento privado entre el deudor y los acreedores" $"$.

64 Cfr. Comisión de las Naciones Unidas para el derecho mercantil internacional (CNUDMI). Documentos del Grupo de Trabajo V. disponible en http: //www.uncitral. org/uncitral/es/ commission/ working_groups/5 Insolvency.html.

65 Destacamos acá, como una figura relacionada con los procesos de insolvencia, en la que también se da la imposición de decisiones, la del cramdown del derecho anglosajón, adoptada en otros países con algunas variantes, que se encuentra en la Guía legislativa de la CNUDMI sobre el régimen de la insolvencia, y que apunta al "aplastamiento" de ciertas categorías de acreedores, con el fin de salvar a la empresa insolvente. Eso sí, la misma difiere mucho de la validación judicial de los acuerdos privados de reorganización, objeto del presente artículo. (Cfr. IgnaCio A Escuti \& Francisco Junyent Bas. Derecho concursal. Págs. 375-417. Buenos Aires: Editorial Astrea. $1^{a}$ edición. (2006)).

66 Milberg. Acuerdos preconcursales, ED, 120-880. Citado por SAntiago C. Fassi \& Marcelo Gebhardt.

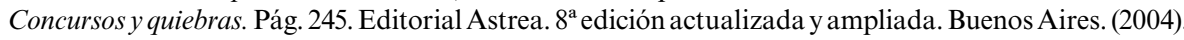




\section{CONCLUSIONES}

Una de las características, por lo menos en teoría, de la validación judicial de acuerdos privados, es su celeridad, debido a que por regla general sólo se acude a dicho procedimiento cuando se tiene celebrado el acuerdo entre el deudor y los acreedores. Por lo tanto, tal figura estaría destinada a convertirse en una vía expedita para lograr acuerdos de reorganización de manera ágil, eficiente y efectiva. Sin embargo, en la práctica es claro que ello sólo es cierto si media una adecuada asesoría, pues muchos de los procesos se han visto dilatados por cuanto se formulan objeciones a la determinación de derechos de voto, la calificación y graduación de créditos y el inventario de bienes, que han obstaculizado la agilidad pretendida por las normas. ${ }^{67}$

Por otro lado, los costos del procedimiento tenderían a disminuir en comparación con los del procedimiento judicial de reorganización, en la medida en que no se requiere la participación del promotor establecido en la Ley 1116 del 2006 para dichos procesos, cuyos honorarios suelen ser elevados. Adicionalmente, debido a que en principio el procedimiento está llamado a ser más ágil, los costos procesales de desgaste y de oportunidad también deberían tender a disminuir. Sin embargo, se reitera, gran parte de la clave del éxito de la figura residiría en la adecuada asesoría de expertos independientes, cuyos honorarios podrían llegar a ser superiores a los costos que tradicionalmente implica un proceso judicial de reorganización.

También se destacan como fortalezas de la figura, entre otras: i) el hecho de que sea necesario el voto del deudor para que se entienda aprobado el acuerdo, lo cual no existe en los acuerdos judiciales de reorganización, en los cuales sólo votan los acreedores internos, pero el deudor como tal no puede ejercer ningún tipo de veto respecto de condiciones que estime que no podrá cumplir; ii) la producción de efectos desde la presentación de solicitud de validación del acuerdo privado; iii) la posibilidad de iniciar negociaciones con una parte de los acreedores, siempre que se notifique a los demás con la antelación mínima exigida por el Decreto 1730 del 2009; iv) la protección al deudor cuando las amenazas contra su patrimonio durante la etapa de negociación del acuerdo impliquen riesgo de no celebración del mismo, como lo regula el parágrafo del artículo 21 del Decreto 1730 del 2009; y v) la facilitación de condiciones para solicitar la admisión al proceso de validación,

67 De acuerdo con información suministrada por la Superintendencia de Sociedades, a la fecha de elaboración de este artículo, se habían iniciado en todo el país quince (15) procesos de validación judicial de acuerdos privados desde la entrada en vigencia de la Ley 1116 del 2006. Han culminado seis (6), cuatro (4) con autorización (uno en Bogotá, dos en Barranquilla y uno en Cali); dos (2) terminados sin autorización en Bogotá, y los demás se encuentran en etapa de resolución de objeciones y uno en estudio para admisión. 
en comparación con los requisitos necesarios para solicitar la admisión a un proceso judicial de reorganización.

Sin embargo, la mayor fortaleza de la figura reside en el hecho de que a través de un proceso judicial muy sencillo y de única instancia, un acuerdo privado está llamado a obligar a la totalidad de los acreedores de un deudor insolvente, así hayan estado ausentes o hayan sido disidentes con respecto a la decisión tomada por la mayoría. Es un reflejo de lo que la doctrina ha denominado "la solución no judicial o extrajudicial" de los problemas de la insolvencia ante los inconvenientes que se han reconocido en los mecanismos judiciales, todo ello dentro de un marco eminentemente contractualista, como se explicó en el acápite tercero ${ }^{68}$. Y tal vez uno de los elementos que refuerzan con mayor intensidad esta característica es el hecho de que la no autorización de la validación del acuerdo privado no implica el inicio del proceso de liquidación del patrimonio del deudor insolvente, sino que se le permite tramitar un nuevo proceso de validación de acuerdo privado o un acuerdo de reorganización dentro de un proceso judicial; por el contrario, si el acuerdo es autorizado, goza de todos los efectos de un acuerdo obtenido dentro del marco judicial, incluyendo la consecuencia de liquidación del patrimonio del deudor, si tal acuerdo llegare a ser incumplido, lo cual garantiza la seriedad de la figura frente a los acreedores.

El entorno más favorable para los acuerdos privados de reorganización estaría dado por tener regímenes efectivos de insolvencia y de ejecución ${ }^{69}$, pues en la medida en que los procesos formales o judiciales de insolvencia sean más eficientes y efectivos, los acuerdos privados van a constituirse cada vez más en una mejor alternativa de reorganización. En efecto, si bien el fracaso del proceso de validación judicial no conlleva la amenaza de la liquidación, sí está prevista una "sanción" y es la posibilidad del inicio de un proceso judicial de insolvencia, lo que en la práctica representa un incentivo importante para tratar de llegar a una negociación privada por parte de los acreedores y el deudor.

Obviamente, la figura no está dotada sólo de fortalezas, sino que también son identificables ciertas debilidades de la misma. En efecto, una de las principales falencias que se encuentran está relacionada con los efectos de la admisión de la solicitud de validación. Así, mientras como consecuencia del inicio de un proceso judicial de reorganización, los procesos ejecutivos o de cobro que se estaban llevando en contra son remitidos al juez del concurso, para que éste los incorpore al proceso concursal y, si es del caso, levante las medidas cautelares practicadas dentro de tales procesos ejecutivos o de

68 Cfr. Juan José Rodríguez Espitia. Nuevo régimen de insolvencia. Págs. 587-588. Universidad Externado de Colombia. 1a. edición. Bogotá D.C. (2007).

69 Banco Mundial. Principios y lineas rectoras para sistemas eficientes de insolvencia y de derechos de los acreedores. Pág. 62. (2001). 
cobro, de manera que tales recursos queden a disposición del deudor, para el desempeño de sus actividades ${ }^{70}$, en los procesos de validación judicial de acuerdos privados, los procesos ejecutivos no se remiten sino que simplemente se suspenden, como claramente lo dispone el artículo 26 del Decreto 1730 del 2009. Lo anterior es lógico, por cuanto si el acuerdo privado no es finalmente autorizado dentro del proceso de validación, los procesos ejecutivos deben continuar, como se deduce del artículo 27 del Decreto 1730 del 2009, pues no hay lugar al inicio del proceso de liquidación del patrimonio del deudor, como sí ocurre cuando un acuerdo celebrado dentro de un proceso judicial no es confirmado por el juez del concurso. Sin embargo, esta suspensión y no remisión de los procesos ejecutivos o de cobro, como consecuencia de la apertura del proceso de validación judicial del acuerdo privado, impide que se puedan levantar las medidas cautelares practicadas y que tales recursos puedan ser utilizados por el deudor para el financiamiento de su operación.

Igualmente se identifica como una posible debilidad de la figura el hecho de que al estar obligados a incluir no sólo las obligaciones causadas hasta el momento de inicio de las negociaciones sino todas las obligaciones causadas hasta el momento de celebración del acuerdo privado, como lo hace el artículo 22 del Decreto 1730 del 2009, se introduce un elemento que podría distorsionar las negociaciones, pues las mayorías decisorias no serían del todo claras y sería muy difícil actualizar día a día la calificación y graduación y créditos y la determinación de derechos de voto. También se identifica como debilidad el hecho de que la figura no estaría diseñada para deudores con la mayoría decisoria de sus acreencias dispersas en muchos deudores, pues se dificulta para ellos la celebración del acuerdo privado, por lo cual la figura estaría restringida para aquellos eventos en que la mayoría decisoria estuviera concentrada en un número no muy grande de acreedores.

Por último, se señala como debilidad de la figura el hecho de que hay dudas sobre la legalidad y constitucionalidad del Decreto 1730 del 2009, pues se ha sostenido que el Gobierno excedió las facultades otorgadas por la Constitución y la ley, ya que en ningún momento el artículo 84 de la Ley 1116 del 2006 facultó al Gobierno para expedir una reglamentación que excede lo dispuesto por la ley. Sin embargo, si el Decreto 1730 del 2009 llegare a ser objeto de alguna declaración que imposibilitara su aplicación, tal situación no sería obstáculo para que la figura de validación judicial de acuerdos privados pudiera seguir aplicándose ${ }^{71}$.

Se puede concluir que las bondades de la figura son mayores que sus debilidades, pues la misma se constituye en un mecanismo que deberían

70 Ley 1116 del 2006. Artículo 21.

71 En efecto, de acuerdo con la información obtenida en la Superintendencia de Sociedades, hay un acuerdo privado que fue objeto de autorización judicial que surtió todo el procedimiento antes de la expedición del Decreto 1730 del 2009, y que se encuentra actualmente en ejecución. 
surtir todos los deudores insolventes que tengan concentradas sus mayorías decisorias en no muchos acreedores, una vez agotado el escenario de un acuerdo estrictamente privado, pues no se corren los mismos riesgos que en un proceso judicial de reorganización, se incentiva la participación activa y constructiva de los acreedores en la solución del problema, por oposición a la confrontación y estigmatización que suelen presentarse en los procesos judiciales de reorganización, y se privilegia la autonomía privada sobre la intervención del Estado en la solución de los problemas de la insolvencia, con la consecuente disminución en costos que ello implicaría, por lo menos en teoría, reflejo ello de la realidad y tendencia hacia la "privatización" que se está viviendo en materia de derecho concursal72. Eso sí, resaltamos el hecho de que el éxito en la utilización de la figura depende en gran parte de una buena asesoría y planeación que garanticen la consecución de los fines perseguidos.

72 El fenómeno de la "privatización" del derecho concursal siempre encontrará como límite el concepto de orden público, esencialmente variable, como lo expone el profesor MUÑoz LAVERDE cuando afirma: “(...) hablar de autonomía privada es hablar de orden público. Son, desde su origen, conceptos inescindibles. Como se verá, la autonomía privada siempre se la ha supeditado al orden público. (...) Y además de no ser una noción necesariamente legal, no es tampoco invariable. En efecto, el transcurso del tiempo, de un lado, y las distintas culturas, costumbres y etnias, de otro, hacen que no pueda aseverarse que el orden público sea inmutable. Lo que ayer no ofendía el orden público, hoy puede ser absolutamente rechazado en una sociedad. En sentido contrario, lo que antes podía verse como contrario al orden fundamental de una sociedad hoy puede ser considerado normal y aun deseable. Y lo que para un específico núcleo social es corriente y usual puede ser desaprobado drásticamente por otro que tenga un arraigo cultural diferente, así sea dentro de un mismo país". (Sergio Muñoz Laverde. El postulado de la autonomía privada y sus límites frente al constitucionalismo colombiano contemporáneo. Ponencia en el Congreso Internacional "Neoconstitucionalismo y derecho privado. El debate" realizado los días 13, 14 y 15 de septiembre del 2006 por la Facultad de Ciencias Jurídicas de la Pontificia Universidad Javeriana. Págs. 256 y 259. Biblioteca Jurídica Diké. $1^{a}$ edición. Bogotá D.C. (2008)). 


\section{BIBLIOGRAFÍA}

AA.VV. Acuerdo preventivo extrajudicial del deudor y sus garantes. En Alfredo Rovira (Director). Empresa en crisis. Págs. 109-152. Buenos Aires. Editorial Astrea. 1a edición. (2005).

Banco Mundial. Principios y líneas rectoras para sistemas eficientes de insolvencia y de derechos de los acreedores. Pág. 62. (2001).

Pablo C. Barbieri. Procesos Concursales. Pág. 328. Buenos Aires: Editorial Universidad. $1^{\text {a }}$ edición. (1999).

Pablo C. Barbieri. Nuevo régimen de concursos y quiebras. Buenos Aires. Universidad de Buenos Aires. $2^{\text {a }}$ edición. (1997). En Pablo Barbieri. Procesos concursales. Pág. 331. Buenos Aires. Editorial Universidad. $1^{\text {a }}$ edición. (1999).

Gustavo Cuberos Gómez. Comentarios al régimen de concordatos comerciales - Decreto 350 de 1989. Bogotá D.C. Ediciones Doctrina y Ley. $2^{\mathrm{a}}$ edición actualizada. (1993).

Ignacio A. Escuti \& Francisco Junyent Bas. Derecho concursal. Págs. 375-417. Buenos Aires. Editorial Astrea. $1^{\mathrm{a}}$ edición. (2006).

Efraín Hugo Richard. Insolvencia societaria. Pág. 39. Buenos Aires. Lexis Nexis Argentina S.A. $1^{\text {a }}$ edición. (2007).

Álvaro Isaza Upegui y Álvaro Londoño Restrepo. Comentarios al régimen de insolvencia empresarial - Ley 1116 del 2006. Bogotá D.C. Legis Editores S.A. 2ª edición. (2008).

Hildebrando Leal Pérez. Los procesos concursales y los acuerdos de reestructuración empresarial. Bogotá D.C. Editorial Leyer Ltda. $4^{\text {a }}$ edición. (2001).

Darío Londoño Saldarriaga. El concordato preventivo. Bogotá D.C. Editorial Temis, S.C.A. $1^{\text {a }}$ edición. (1982).

Milberg. Acuerdos preconcursales, ED, 120-880. En Santiago C. Fassi y Marcelo Gebhardt. Concursos y quiebras. Pág. 245. Buenos Aires. Editorial Astrea. $8^{a}$ edición actualizada y ampliada. (2004).

Sergio Muñoz Laverde. El postulado de la autonomía privada y sus límites frente al constitucionalismo colombiano contemporáneo. Ponencia en el Congreso Internacional "Neoconstitucionalismo y derecho privado. El debate", realizado los días 13, 14 y 15 de septiembre del 2006 por la Facultad de Ciencias Jurídicas de la Pontificia Universidad Javeriana. Biblioteca Jurídica Diké. Bogotá D.C. $1^{\mathrm{a}}$ edición. (2008).

Guillermo Ospina Fernández. Régimen general de las obligaciones. Pág. 80. Editorial Temis S.A. Bogotá D.C. (1976).

Guillermo Ospina Fernández y Eduardo Ospina Acosta. Teoría general del contrato y de los demás actos o negocios jurídicos. Editorial Temis S.A. Bogotá D.C. (1994).

Efraín Hugo Richard. Insolvencia societaria. Págs. 162-168. Buenos Aires. Lexis Nexis Argentina S.A. $1^{\text {a }}$ edición. (2007).

Julio C. Rivera, Horacio Roitman \& Daniel Vítolo. Concursos y quiebra. Ley 24.522. Pág. 97. Santa Fe. Rubinzal-Culzoni Editores. (1995).

Juan José Rodríguez Espitia. Nuevo régimen de insolvencia. Universidad Externado de Colombia. Bogotá D.C. $1^{\mathrm{a}}$ edición. (2007). 
Jesús María Sanguino Sánchez. Cesación de pagos en los procedimientos concursales. Págs. 9-12. Ediciones Librería del Profesional. Bogotá D.C. 1 ${ }^{\text {a }}$ edición. (1982).

Diana lucía Talero Castro. Predictibilidad, un elemento esencial de un régimen de insolvencia moderno. En Empresas colombianas: actualidad y perspectivas. Pág. 169. Superintendencia de Sociedades. Bogotá D.C. $1^{\text {a }}$ edición. (2009).

\section{Normas}

Decreto 1730 del 2009. Artículos 20, 21, parágrafo, 22, 23 numeral 6 $6^{\circ}, 27,29$ inciso $2^{\circ}$.

Exposición de motivos de la Ley 550 de 1999. Transcrita en Claudia Álvarez Vejarano. Ley 550 - Manual de interpretación. Págs. 117-132. 3R Editores Ltda. Bogotá D.C. $1^{\text {a }}$ edición. (2000).

Ley 1116 del 2006. Artículos 1, 2º 21, 31, 37 y 57.

\section{Páginas web}

Comisión de las Naciones Unidas para el derecho mercantil internacional (CNUDMI). Presentación de la Ley modelo de la CNUDMI sobre la insolvencia transfronteriza con la guía para su incorporación al derecho interno. En http://www.uncitral.org/ uncitral/es/uncitral_texts/insolvency/1997Model.html.

Comisión de las Naciones Unidas para el derecho mercantil internacional (CNUDMI). Documentos del Grupo de Trabajo V. disponible en http: //www.uncitral. org/uncitral/ es/commission/ working_groups/5 Insolvency.html. 